\title{
RACK1 on and off the ribosome
}

\author{
ALEX G. JOHNSON, ${ }^{1,2,5}$ CHRISTOPHER P. LAPOINTE, ${ }^{1,5}$ JINFAN WANG, ${ }^{1}$ NICHOLAS C. CORSEPIUS, ${ }^{1}$ \\ JUNHONG CHOI, ${ }^{1,3}$ GABRIELE FUCHS ${ }^{4}$ and JOSEPH D. PUGLISI ${ }^{1}$

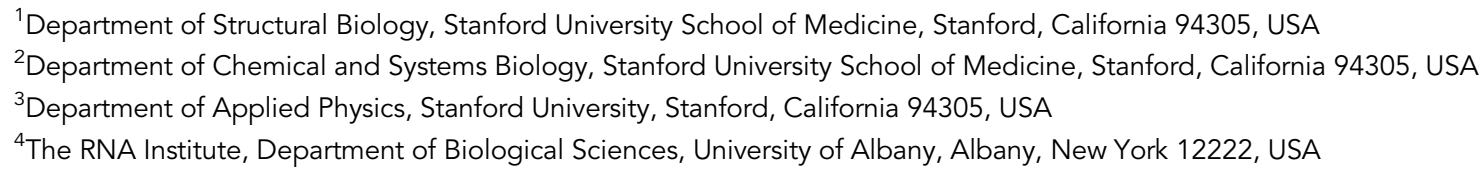

\section{ABSTRACT}

Receptor for activated C kinase 1 (RACK1) is a eukaryote-specific ribosomal protein (RP) implicated in diverse biological functions. To engineer ribosomes for specific fluorescent labeling, we selected RACK1 as a target given its location on the small ribosomal subunit and other properties. However, prior results suggested that RACK1 has roles both on and off the ribosome, and such an exchange might be related to its various cellular functions and hinder our ability to use RACK1 as a stable fluorescent tag for the ribosome. In addition, the kinetics of spontaneous exchange of RACK1 or any RP from a mature ribosome in vitro remain unclear. To address these issues, we engineered fluorescently labeled human ribosomes via RACK1, and applied bulk and single-molecule biochemical analyses to track RACK1 on and off the human ribosome. Our results demonstrate that, despite its cellular nonessentiality from yeast to humans, RACK1 readily reassociates with the ribosome, displays limited conformational dynamics, and remains stably bound to the ribosome for hours in vitro. This work sheds insight into the biochemical basis of RPs exchange on and off a mature ribosome and provides tools for single-molecule analysis of human translation.

Keywords: ribosome; translation; human; RACK1; IRES; single-molecule fluorescence

\section{INTRODUCTION}

Protein synthesis by the ribosome is a heterogeneous and dynamic process across all kingdoms of life. As such, translation systems are particularly well-suited for single-molecule analysis, given its ability to resolve kinetics and parse out heterogeneous pathways through real-time measurements. Although nearly two decades of studies have clarified and expanded the mechanisms of bacterial translation, very few tools exist to study this process in human systems. A critical absence is an approach for high-efficiency labeling of human ribosomes with fluorescent dyes or other labels with minimal perturbation of ribosomal function or structure.

The eukaryotic ribosome contains $\sim 80$ ribosomal proteins (RPs) and four strands of ribosomal RNA (rRNA) organized into large (60S) and small (40S) subunits (Melnikov et al. 2012). The ribosome is often considered a particle of stable composition, and it is thus surprising that nearly $20 \%$ of ribosomal proteins (RPs) are nonessential in budding yeast (Steffen et al. 2012), implying that some

\footnotetext{
${ }^{5}$ These authors contributed equally to this work.

Corresponding author: puglisi@stanford.edu

Article is online at http://www.rnajournal.org/cgi/doi/10.1261/rna. 071217.119.
}

RP-deficient ribosomes are capable of supporting cellular life. While much less is known about RP essentiality in mammals, preliminary work suggests that several RPs are nonessential within mammalian cell lines (Supplemental Fig. 1A; Blomen et al. 2015). This realization was our gateway into the fluorescent labeling of human ribosomes, wherein we leveraged the cellular nonessentiality of eS25 to genetically engineer a cell line bearing ribosomes labeled at that protein (Fuchs et al. 2015). However, this method has several limitations: In particular it relies on a large protein tag (SNAP-tag) that more than doubles the size of eS25, which may obscure analyses of conformational dynamics and reduce ribosome labeling efficiency through misfolding or proteolysis of the fusion protein. We were further concerned that such a system might artificially perturb or fail to monitor some translation events given the location of eS25 near the ribosomal $\mathrm{E}$ site and that sub-populations of cellular ribosomes are sub-stoichiometric for eS25 (Shi et al. 2017; Van De Waterbeemd et al. 2018).

(C) 2019 Johnson et al. This article is distributed exclusively by the RNA Society for the first 12 months after the full-issue publication date (see http://rnajournal.cshlp.org/site/misc/terms.xhtml). After 12 months, it is available under a Creative Commons License (Attribution-NonCommercial 4.0 International), as described at http:// creativecommons.org/licenses/by-nc/4.0/. 
To address these issues, our focus turned to another eukaryote-specific RP: receptor for activated C kinase 1 (RACK1). Given its prominent position at the surfaceexposed region of the $40 \mathrm{~S}$ ribosomal subunit (Fig. 1A), we predicted that labeling at RACK1 would be less likely to perturb translation events. Nonetheless, RACK1 has been implicated in diverse biological roles (Gibson 2012), and we were concerned that its labeling might inadvertently alter ribosome function. For one, RACK 1 is a WD40-domain protein, a domain seen broadly in cellular signaling proteins and often implicated in a "scaffolding" role (Stirnimann et al. 2010). While RACK1 is nonessential for cellular life from yeast to humans (Jha et al. 2017) (although a full knockout is embryonically lethal in mice [Volta et al. 2013]), its loss or depletion leads to altered cellular signaling (Gibson 2012; Nielsen et al. 2017), translational rewiring (Thompson et al. 2016; Gallo et al. 2018), misregulated ribosome-associated quality control (Juszkiewicz and Hegde 2017; Matsuo et al. 2017; Sitron et al. 2017; Sundaramoorthy et al. 2017), and protection against multiple viruses (Majzoub et al. 2014; Hafirassou

A
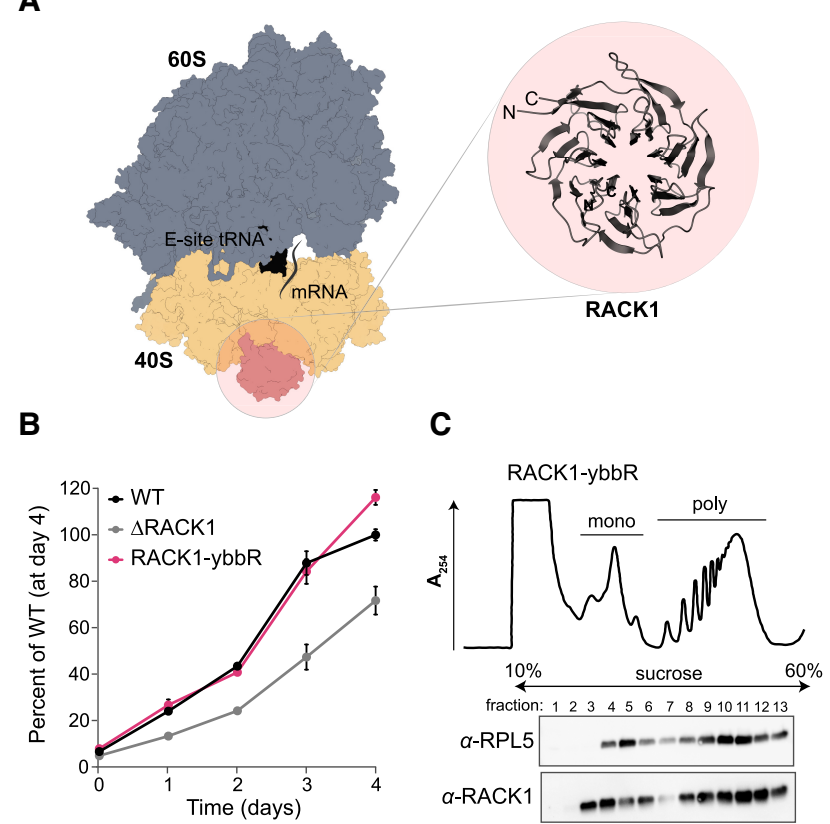

FIGURE 1. RACK1-ybbR incorporates into translating ribosomes in human cells. (A) Structure of the human ribosome (PDB 6ek0). The $40 \mathrm{~S}$ (tan) and 60S (blue) ribosomal subunits, RACK1 (pink), mRNA (gray line), and an E-site tRNA (black) are indicated. The WD40 repeat structure of RACK1 is illustrated in the inset with a ribbon depiction (also from PDB 6ek0). There are one and three unresolved amino acids on the amino- and carboxy-termini of RACK1, respectively. (B) Plot of the proliferation of the indicated cell lines as measured by an MTT cell proliferation assay relative to the wild-type cells at day 4 . Error bars represent the $95 \% \mathrm{Cl}(n=10)$. (C) UV absorbance trace (at $254 \mathrm{~nm}$ ) of polysome profiling and associated western blot analysis of the RACK1-ybbR cell line. "Mono" and "poly" refer to peaks that correspond to monosomes and polysomes, respectively. et al. 2017; Jha et al. 2017; Kim et al. 2018). These functional aspects of RACK1 suggest a need for a minimal perturbation of RACK1 for labeling and subsequent analyses to demonstrate that cellular function is not perturbed.

Another confounding factor for labeling ribosomes at RACK1 originates from cellular studies that attempt to distinguish the ribosomal and nonribosomal functions of the protein (Gibson 2012; Nielsen et al. 2017). Confusion here is warranted-in stationary phase yeast, the RACK1 homolog Asc1p is detected free in the cytosol (Baum et al. 2004), and some of its properties listed above seem to suggest an extra-ribosomal role (Warner and Mclntosh 2009). The potential for RACK1 exchange from the ribosome is also suggested by it being one of the final proteins to incorporate during ribosome biogenesis (Larburu et al. 2016), yet it is also a stoichiometric component of most eukaryotic ribosomes studied to date (Sengupta et al. 2004; Rabl et al. 2011; Shi et al. 2017; Van De Waterbeemd et al. 2018). However, a notable exception is in Plasmodium falciparum (the malaria parasite) where RACK1 is expressed and required for intracellular survival (Blomqvist et al. 2017), but paradoxically not present in any ribosome structure (Wong et al. 2014; Sun et al. 2015). Thus, RACK1 embodies suggestive qualities of an exchangeable RP, and these properties could be intimately linked with its function.

Here our first goal was to establish a stable and stoichiometric human ribosome labeling site, but given the uncertain stability of RACK1 on the ribosome and the unique opportunity it provided, we sought to harness RACK1 to study the biochemical basis for RP exchange. Although a few studies have demonstrated the possibility for RP incorporation into ribosomes lacking an RP (Lieberman et al. 2000; Cornish et al. 2008; Kossinova et al. 2008), the kinetics of this process have not been investigated in the context of mature ribosomes in vitro. After labeling human ribosomes at RACK1 and thereby further facilitating biophysical analyses of translation, we devised a system to track RACK 1 flux on and off the ribosome to address this knowledge gap. Collectively, our results demonstrate the benefit of compact and targeted labeling schemes for the human ribosome, which is generalizable to other RPs. By following the dynamics of RACK 1 association to and dissociation from ribosomes with single-molecule spectroscopy, we further establish an in vitro benchmark for the biochemical stability of an integral RP.

\section{RESULTS}

RACK1 is organized into a symmetric and well-folded structure when free in solution (Fig. 1A) as revealed by crystallographic studies on proteins expressed in and purified from E. coli (Bjørndal et al. 2003; Nery et al. 2006; Coyle et al. 2009; Ruiz Carrillo et al. 2012). Whereas most other RPs are small and very basic $(\mathrm{pl} \approx 10-11)$, 
RACK1 has a relatively large molecular weight and near neutral pl (Supplemental Fig. 1B,C). In our hands, the nonessential RPs eS25 and eL22 may be expressed in E. coli when fused to maltose-binding protein (MBP), but readily precipitate at physiological salt concentrations. Thus, based on its biochemical tractability and cellular nonessentiality, we developed a strategy to fluorescently label RACK1 on and off the ribosome as a strategy to label intact ribosomes and to monitor its ribosome association as a free protein. To ensure a compact labeling strategy, we used site-specific labeling with the 11 amino acid ybbRtag (Fig. 1A; Yin et al. 2006).

We first tested whether ybbR-tagged RACK1 is functional on ribosomes in cell culture. Using lentiviral transduction, we expressed carboxy-terminally ybbR-tagged RACK1 in a previously generated knockout of RACK1 ( $\triangle$ RACK1) in the human HAP1 cell line (Jha et al. 2017), and examined wild-type, $\triangle R A C K 1$, and RACK1-ybbR cell lines using cell proliferation and polysome profiling assays. Whereas the $\triangle R A C K 1$ cell line grows slower relative to the wild-type cell line (Fig. 1B; Supplemental Fig. 2A), expression of RACK1-ybbR in the $\triangle$ RACK1 cell line recovered cell proliferation to wild-type levels. To probe its functionality, we examined the three cell lines using polysome profiling and western blot analyses. RACK1 and RACK1-ybbR were present in both monosome and polysome fractions, with minimal free protein detected from the post-nuclear cell lysate (Fig. 1C; Supplemental Fig. 2B). In the $\triangle$ RACK1 cell line, we observed an increase in the monosome peak relative to the polysome peaks, possibly indicating alterations in the pool of active ribosomes (Supplemental Fig. 2B). Thus, RACK1-ybbR rescues the $\triangle$ RACK1 growth defect and is incorporated into actively translating ribosomes.

\section{Fluorescent labeling of intact $40 \mathrm{~S}$ ribosomal subunits via RACK1-ybbR}

RACK1 is a prominent feature on the surface-exposed region of the $40 S$ subunit, where it contacts RPs uS3, uS9, and eS17, and helices 39 and 40 of 18 S rRNA, and may facilitate interactions with numerous signaling proteins (Nielsen et al. 2017). It is proximal to the mRNA entry and exit channels (Fig. 2A), and adjacent to the region bound by the HCV IRES, which directly binds the 40S subunit with high-affinity (Johnson et al. 2017). The aminoand carboxy-termini of RACK1 are in close proximity and surface accessible, so the carboxy-terminal ybbR-tag on RACK1 should be accessible to SFP synthase (Yin et al. 2006) on the mature $40 S$ ribosomal subunit (Fig. 2B,C). To test this, we purified ribosomes from RACK1-ybbR expressing cells, identified optimal conditions for labeling (Supplemental Fig. 3A,B), and routinely achieved labeling efficiencies $>50 \%$ on purified ribosomal subunits.

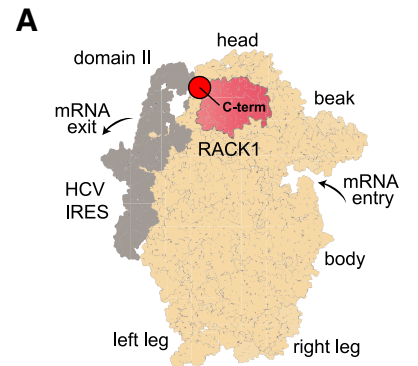

B

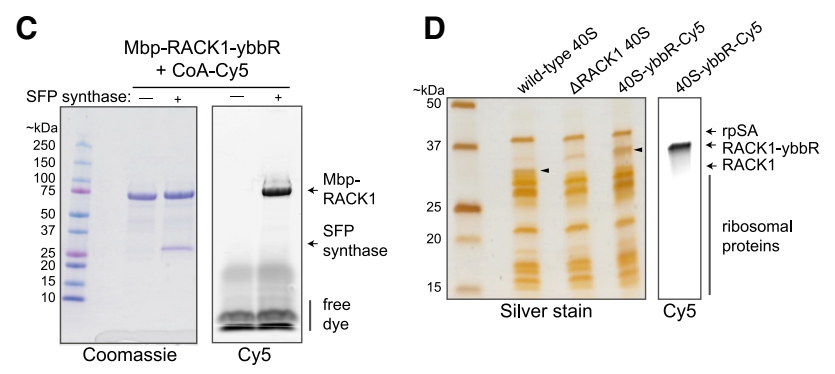

FIGURE 2. Labeling ribosome-bound and recombinant RACK1-ybbR with fluorophores using SFP synthase. (A) Model structure of the human $40 S$ ribosomal subunit (tan) bound to the HCV IRES (gray), with RACK1 highlighted in pink (PDB 5a2q). Key locations on the ribosome and IRES are indicated, with this view focused on the solvent-exposed surface of the $40 \mathrm{~S}$ subunit. (B) Model of human RACK1 structure with the carboxy-terminal ybbR peptide tag indicated. RACK1-ybbR was site-specifically labeled by incubation with SFP synthase and CoACy3 or CoA-Cy 5 conjugated dye substrates. (C) Image of a representative gel that was first scanned for Cy 5 fluorescence (right) and subsequently stained with Coomassie blue (left) following SDS-PAGE analysis of RACK1-ybbR post-labeling with and without SFP synthase. (D) Image of a representative gel that was first scanned for Cy 5 fluorescence (right) and subsequently silver stained (left) following SDSPAGE analysis of the indicated 405 ribosomal subunits, with the RACK1 bands indicated by arrows on both images.

To determine whether RACK1-ybbR containing 40S ribosomal subunits were biochemically intact, we characterized them alongside wild-type and $\triangle R A C K 1$ subunits using denaturing and native gel assays. By SDS-PAGE, we observed a single fluorescent band in the 40S-RACK1-ybbR sample that matched the migration pattern of recombinant RACK1-ybbR (Fig. 2D; Supplemental Fig. 3C). This RACK1 band with an increased molecular weight was detected in $40 S$ ribosomal subunits at a level similar to endogenous RACK1 in wild-type 40S subunits by immunoblotting (Supplemental Fig. 3D). As expected, no RACK1 was detected in the $\triangle$ RACK1 $40 \mathrm{~S}$ subunits. Several other RPs also exhibited similar levels across the three $40 \mathrm{~S}$ samples; however, we observed a modest increase in a higher molecular weight band for uS3 in $\triangle \mathrm{RACK} 1$ relative to wild-type $40 S$ subunits, which was returned to near wild-type levels in 40S-RACK1-ybbR subunits (Supplemental Fig. 3D). The carboxyl terminus of uS3 directly contacts RACK1, and this band may represent a post-translational modification to uS3 that was increased in the absence of RACK1. Finally, using native-gel electrophoresis (Johnson et al. 
2018), we found that 40S-RACK1-ybbR subunits bound the HCV IRES with similar efficiency as to WT 40 S subunits, and they were competent to form $\mathrm{Mg}^{2+}$-driven (Lancaster et al. 2006; Yamamoto et al. 2014) 80 S complexes on the IRES (Supplemental Fig. 3E). In summary, 40S-RACK1-ybbR ribosomes are nearly identical in composition to wild-type subunits and functional in preliminary biochemical assays.

\section{A reliable smFRET signal for the presence of RACK1 within $40 S$ subunits}

Given the high-affinity between the $40 \mathrm{~S}$ subunit and HCV IRES and its utility for specific immobilization of human ribosomes (Fuchs et al. 2015; Johnson et al. 2018), we next examined the suitability of 40S-RACK1-ybbR ribosomal subunits for single-molecule analyses in the context of the HCV IRES. Domain II of the IRES is predicted to be within smFRET distance with the carboxyl terminus of RACK1, despite there being no direct RNA-RACK1 interaction (Fig. 3A). We therefore used segmental labeling to attach fluorophores directly to the HCV IRES to generate two versions of the IRES with Cy5 dyes at either the base (C44) or elbow (U56) of domain II (Supplemental Fig. 4A). These positions are predicted to be within the dynamic range of FRET ( $\sim 70$ and $90 \AA$ away from the carboxyl terminus of RACK1 for C44 and U56, respectively (Fig. 3A; Yamamoto et al. 2014; Quade et al. 2015), and allow an approximate triangulation of conformational dynamics within the 40S-IRES complex.

To detect smFRET between RACK1 and the HCV IRES, we immobilized complexes on a Neutravidin-coated quartz slide and imaged them using total internal reflection fluorescence microscopy (TIRFM) and laser excitation of native RACK1-ybbR-Cy3 on the 40 S subunit (Fig. 3B,C; Supplemental Fig. 4B). We observed smFRET to Cy5-IRES (C44) or Cy5-IRES(U56) in 40S-IRES complexes (Fig. 3B). The resulting smFRET signals from both dye pairs were characterized at near- and above-physiological $\mathrm{Mg}^{2+}$ concentrations (2 and $5 \mathrm{mM}$, respectively) (Fig. 3D; Supplemental Fig. 4C-G) and in a $\mathrm{Mg}^{2+}$-driven 80S-IRES complex (Lancaster et al. 2006; Yamamoto et al. 2015) (Supplemental Fig. 4H). Most of the 40S-IRES smFRET efficiency distributions were well-fit by single Gaussian functions, irrespective of the IRES labeling position, with a few best fit by a double Gaussian function (Supplemental Fig. 4I). However, there were relatively rare transitions from low to high FRET states for single complexes across all conditions (Supplemental Fig. 4D-H), some of which notably altered the appearance of the FRET efficiency histogram. As expected, the smFRET efficiency was higher when Cy5IRES(C44) was the acceptor $(20.28)$ in comparison to Cy5-IRES(U56) ( 0.17) (Fig. 3D). In both cases, the mean efficiencies were higher than predicted (Supplemental Fig. 4I), likely attributed to the uncertain, dynamic positions of the dyes on the flexible ends of RACK1. Thus, we conclude that RACK1-ybbR is present at its native position on the $40 S$ subunit, and 40S-RACK1-ybbR ribosomes are amenable to single-molecule analysis.

We previously observed conformational dynamics within the 40S-IRES complex at $5 \mathrm{mM} \mathrm{Mg}^{2+}$ that were absent at a lower $\mathrm{Mg}^{2+}$ concentration and in the presence of translation extracts (Fuchs et al. 2015). However, it was unclear whether these measurements were influenced by the bulky tags used for fluorescent labeling: eS25 was carboxy-terminally labeled with a SNAP tag, which is nearly twice its size; and the HCV IRES was labeled at the 5 ' end by annealing a 24 nt DNA oligo. We thus completed similar analyses using our improved and much more compact RACK1-IRES smFRET signals for comparison. We observed that the smFRET efficiencies between RACK1 and both IRES constructs were modestly shifted when the $\mathrm{Mg}^{2+}$ concentration was raised from 2 to $5 \mathrm{mM}$ (Fig. 3D; Supplemental Fig. 4). There was a minor population of higher FRET efficiency states ( 0.74) for the Cy5-IRES (C44) acceptor at $5 \mathrm{mM} \mathrm{Mg}^{2+}$ that was absent at the lower $\mathrm{Mg}^{2+}$ concentration. This minor population was also absent in the 80S-IRES complex, which instead had a minor population of even higher FRET ( 1.00). Although we currently hesitate to conclude mechanisms from these high FRET states given their rarity and existence at higher-thanphysiological $\mathrm{Mg}^{2+}$ concentrations, the observed changes occur at $\mathrm{Mg}^{2+}$ concentrations that are known to promote the transition from the 40S- to 80S-IRES complex (Lancaster et al. 2006), whereby higher $\mathrm{Mg}^{2+}$ concentration may be a surrogate for conformational transitions normally induced by protein factors. Collectively, our new labeling strategy revealed similar conformational dynamics as observed previously using bulkier labels, illustrating that the intrinsic flexibility of the 40S-IRES complex is still observed with a compact labeling scheme.

We subsequently probed the association of 405 subunits with the HCV IRES using the RACK1-IRES smFRET signals in real-time, and compared the measurements to those made with our prior labeling scheme (Fuchs et al. 2015). We applied a zero-mode waveguide-based (ZMW) system to make real-time smFRET measurements (Chen et al. 2014), and selected the IRES(C44) label since it had higher FRET efficiency with RACK1-ybbR in comparison to IRES(U56). To further improve the signal and ensure an unambiguous binding state, we tested both Cy3 and Cy3.5 as the donor fluorophore. The latter has greater spectral overlap with Cy5 (Buckhout-White et al. 2014) and an increased $R_{0}$, yielding higher FRET intensities at greater distances. We prepared Cy3- and Cy3.5-IRES (C44) RNAs (donors), and native 40S-RACK1-ybbR-Cy5 ribosomal subunits (acceptor), and simultaneously immobilized the labeled IRESs within Neutravidin-coated ZMWs on a single chip with 150,000 ZMWs (RS chip) (Fig. 3E). 40S-RACK1-ybbR at $40 \mathrm{nM}$ was added to the surface of the RS chip after the start of data acquisition, and its 
A

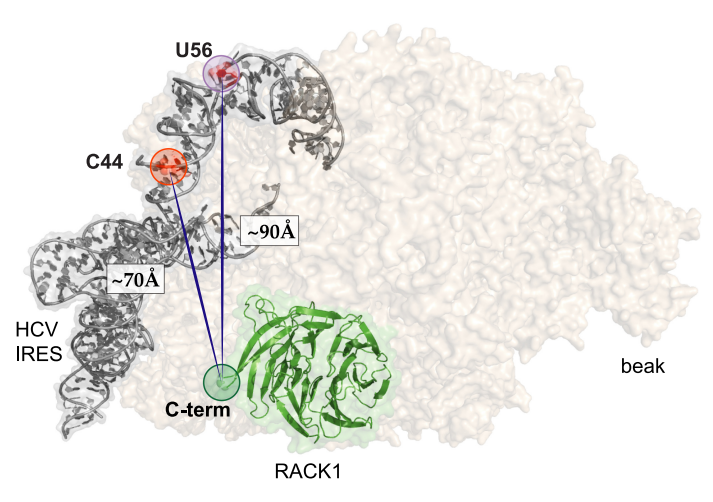

E

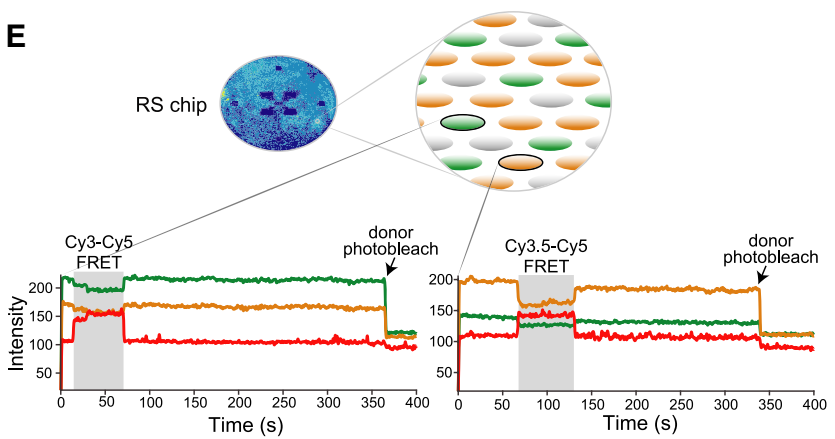

B

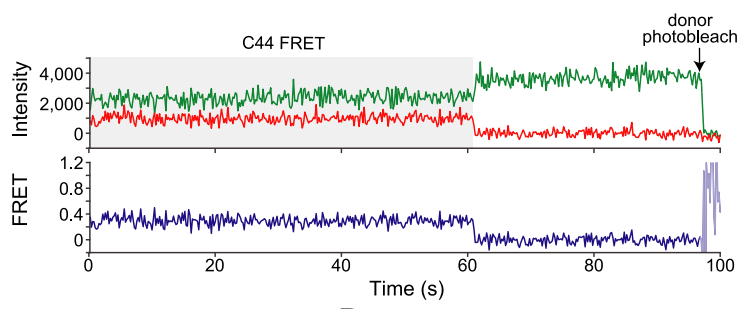

C

D

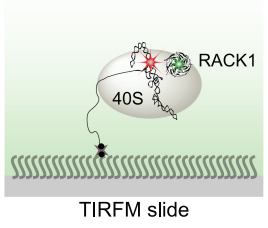

F

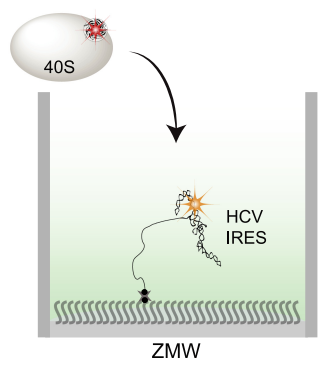

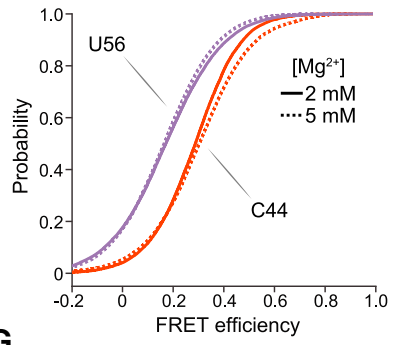

G

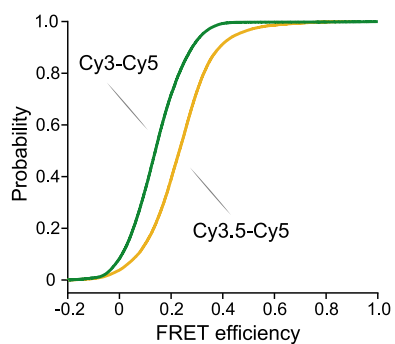

FIGURE 3. RACK1-ybbR is proximal to domain II of the HCV IRES and provides a signal for 40S-IRES association and conformational dynamics on two single-molecule fluorescence platforms. (A) Structural model of the human $40 S$ ribosomal subunit (tan) bound to the HCV IRES (gray), with RACK1 highlighted in green (PDB 5a2q). The carboxyl terminus of RACK1, and the locations of C44 and U56 in the HCV IRES are highlighted, with the measured distance between them indicated. (B) Representative single-molecule fluorescence trace and FRET conversions from TIRFM experiments, with FRET between RACK1-ybbR-Cy3 and IRES(C44-Cy5) highlighted in gray. smFRET was signified by anticorrelated changes in fluorescence intensity of the fluorophores, and single 4OS-IRES complexes were identified via a single-step photobleach in the Cy3 donor signal, indicated by the arrow. (C) Schematic of surface immobilized 40S-RACK1-ybbR-Cy3:Cy5-HCV-IRES complexes on a quartz slide used for TIRFM. (D) Cumulative distribution plot of observed FRET intensities for 40S-RACK1-ybbR-Cy3 with IRES(Cy5-U56, purple) or IRES(Cy5-C44, orange) in the presence of $2 \mathrm{mM}$ (solid lines) or $5 \mathrm{mM} \mathrm{Mg}^{2+}$ (dashed lines). The number of traces analyzed ( $n$ ) for panels $D$ are listed in Supplemental Figure 4I. (E) Schematic of 40S-RACK1-ybbR-Cy5 delivery to surface-immobilized HCV IRES labeled at C44 with Cy3 or Cy3.5 in zero-mode waveguides (ZMWs). The blue oval is the full view of an RS chip that has both IRES(Cy3-C44) and IRES(Cy3.5-C44) immobilized in individual ZMWs on the chip. Below the schematic are example single-molecule fluorescence traces that depict Cy3-Cy5 (left) or Cy3.5-Cy5 (right) upon delivery of 40S-RACK1-ybbR-Cy5 to dual-immobilized IRES(Cy3-C44) and IRES(Cy3.5-C44). The respective FRET events are highlighted in gray, and photobleaching of the donors are indicated by the arrows. (F) Schematic of an individual ZMW showing delivery of 40 S-RACK1-ybbR-Cy5 to a Cy3.5 labeled HCV IRES. (G) Cumulative distribution plots of observed FRET efficiency from 40S-RACK1-ybbR-Cy5 FRET with either IRES(Cy3-C44) (green) or IRES(Cy3.5-C44) (yellow) after delivery to dual-immobilized IRESs. The number of traces analyzed ( $n$ ) for panel $G$ are listed in Supplemental Figure 5D.

association with a single immobilized HCV IRES was detected via appearance of smFRET (Fig. 3E; Supplemental Fig. 5A). As expected, the Cy3.5-Cy5 pair yielded increased smFRET efficiency ( 0.23) relative to Cy3-Cy5 ( 0.14) (Fig. 4F; Supplemental Fig. 5B-D), which was lower than that observed using TIRFM, possibly due to quenching of Cy5 by the aluminum ZMWs (Uemura et al. 2010). $40 \mathrm{~S}$ association times, defined as the time between the start of the data acquisition and appearance of smFRET, and 405 residence times, defined as the length of the smFRET signal, were nearly identical for both Cy3- and Cy3.5-IRES(C44) molecules (Fig. 4D; Supplemental Fig.
$5 E, F)$, and similar to our prior measurements of 40S-IRES association kinetics (Fuchs et al. 2015). Thus, by dualimmobilization of Cy3- and Cy3.5-labeled HCV IRESs in ZMWs, we identified an optimal smFRET pair for our single-molecule analyses in ZMWs and validated a strategy that might enable simultaneous tracking of ribosome recruitment to multiple variant RNAs in a single experiment.

\section{RACK1 association with the $40 \mathrm{~S}$ ribosomal subunit}

The above experiments established the functionality of RACK1-ybbR in native $40 \mathrm{~S}$ ribosomal subunits and a 
A

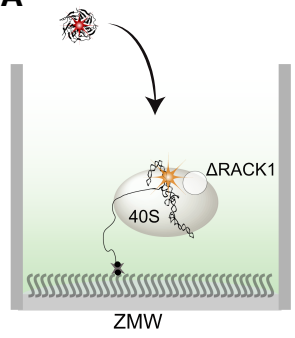

E

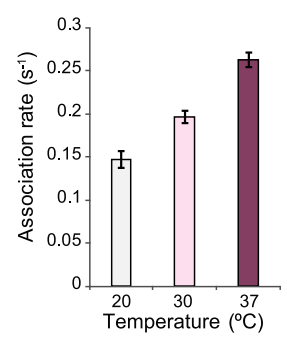

B

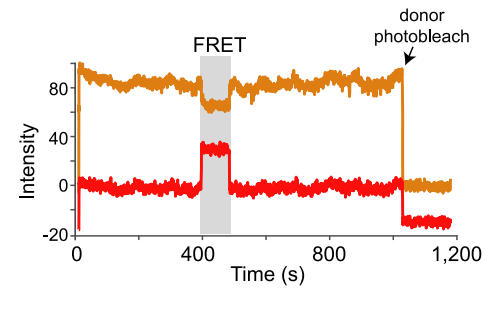

F

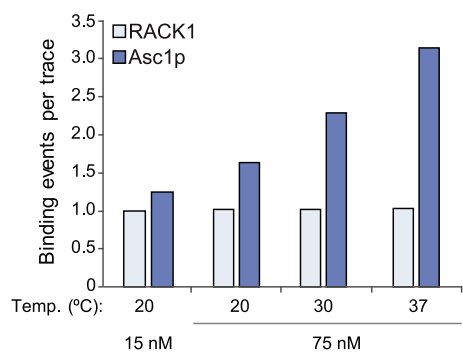

C

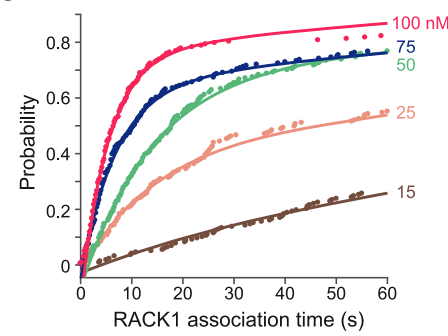

G

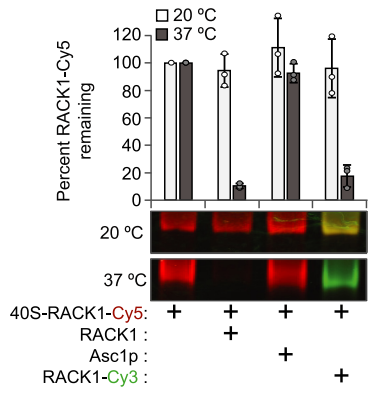

D

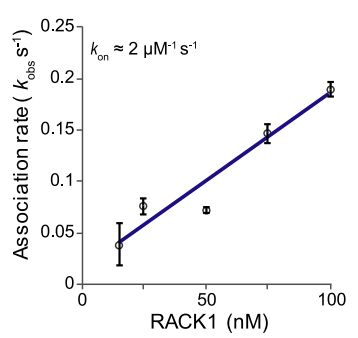

H
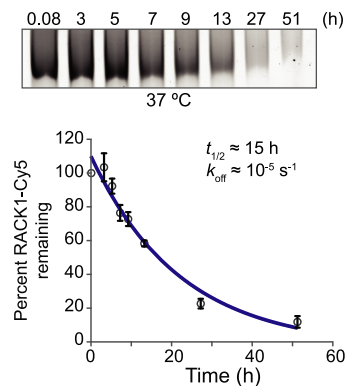

FIGURE 4. Monitoring RACK1 flux by real-time smFRET in ZMWs. (A) Schematic of RACK1 delivery to surface-immobilized $\triangle R A C K 140 S$ in complex with the HCV IRES labeled at C44 with Cy3.5 in ZMWs. (B) Representative single-molecule fluorescence trace for RACK1-ybbR-Cy5 binding to a single $\triangle$ RACK1 40S:Cy3.5-IRES complex indicated by Cy3.5-Cy5 FRET, highlighted in gray. (C) Cumulative distribution plot of observed RACK1 association times from 0 to $60 \mathrm{sec}$. The labels on the right indicate RACK1-ybbR-Cy5 concentration (nM). The lines represent fits to double-exponential functions. (D) Plot of observed RACK1 association rates $\left(k_{\mathrm{obs}}\right)$ of the fast phase at the indicated concentrations. Error bars represent the $95 \%$ confidence interval for each value. The line represents a fit to a linear function, with equation $y=0.0017 x+0.0149$ and $R^{2}=0.9225$, which yielded the indicated association rate $\left(k_{o n}\right)$ for the fast phase. The nonzero intercept may be due to experimental factors such as the presence of unlabeled RACK1-ybbR that competes with the labeled protein (RACK1-ybbR had 70\% labeling efficiency). (E) Plot of observed association rates $\left(k_{o b s}\right)$ for the fast phase at the indicated temperatures upon delivery of RACK1-ybbR-Cy5 at $75 \mathrm{nM}$. Error bars represent the $95 \%$ confidence interval for each value. (F) Plot of the observed number of binding events on a single $\triangle$ RACK1 40S-IRES complex within a single experiment, indicated by smFRET, for RACK1-ybbR-Cy 5 and Asc1p-ybbR-Cy5 delivered at 15 or $75 \mathrm{nM}$ at the indicated temperatures. (G) Native gel electrophoresis analysis of 40S-RACK1-ybbR-Cy5 at $40 \mathrm{nM}$ following competition for $24 \mathrm{~h}$ with recombinant unlabeled RACK1-ybbR and Asc1pybbR at 20-fold excess, and recombinant RACK1-ybbR-Cy3 at 10-fold excess. The gels were analyzed in parallel and are displayed as an overlay of Cy5 (red) and Cy3 (green) fluorescence. The integrated density of each band was quantified using ImageJ, normalized to the respective control sample (lane 1, from left), and the mean $(n=3)$ Cy5 fluorescence was plotted. Error bars represent standard deviation, and circles represent individual data points. $(H)$ Native gel electrophoresis analysis of 40S-RACK1-ybbR-Cy5 at $40 \mathrm{nM}$ following competition after the indicated times with recombinant unlabeled RACK1-ybbR at 20-fold excess. A representative gel is shown and displays Cy5 fluorescence. Each point on the graph below represents the mean fluorescence intensity remaining relative to the $0.08 \mathrm{~h}$ time point, and error bars represent standard deviation. The line represents a fit to an exponential function $\left(R^{2}=0.93\right)$, which yielded $t_{1 / 2}=15 \mathrm{~h} \pm 5 \mathrm{~h}$. The number of traces analyzed $(n)$ for panels $C, E$, and $F$ are listed in Supplemental Figures 9E, 10C.

smFRET pair between RACK1 and the HCV IRES suitable for real-time measurements. We next adapted these tools with a reconstituted system to study RACK1 flux on and off the ribosome. After expression in E. coli, we purified and fluorescently labeled ybbR-tagged RACK1, as well as mutant versions proposed to have reduced association with the ribosome. These included the D107Y mutation (Kuroha et al. 2010), and a phosphomimetic version (S278E) not expected to interfere with ribosome binding (Jha et al. 2017). Of note, the D107Y mutant was less stable in vitro and copurified with E. coli HSP60, suggesting a subpopulation may be misfolded or unstable (Supplemental Fig. 6). Similarly, a second mutant proposed to disrupt the RACK1-ribosome interaction (R36D/K38E) (Sengupta et al. 2004; Coyle et al. 2009) was also recalcitrant to purification, again likely due to decreased stability (Supple- mental Fig. 6). These mutants therefore were unsuitable for single-molecule analysis and suggest revisiting interpretations of the many experiments that have used the mutants to deconvolute ribosomal versus extra-ribosomal roles for RACK1, as previously cautioned (Thompson et al. 2016). To circumvent these issues, we hypothesized that the S. cerevisiae RACK1 ortholog, Asc1p, would bind the human ribosome with weakened affinity relative to RACK1. Asc1p has multiple substitutions in comparison to RACK1 along the interaction interface with the ribosome (Supplemental Fig. 7; Nielsen et al. 2017), and the human protein associated more weakly than Asc1p to ribosomes in live yeast (Gerbasi et al. 2004). We therefore purified and fluorescently labeled Asc1p (Supplemental Fig. 6), yielding a stable and potentially lower-affinity comparison to wild-type RACK1. Following a similar rationale, we also 
attempted to purify the RACK1 ortholog from P. falciparum, which is absent from structures of its ribosome, but we were unable to purify the protein for similar reasons to the human mutants.

With a small panel of RACK1 proteins predicted to have a range of affinities with the human ribosome in hand, we next tested whether the different RACK1 proteins associated with wild-type and RACK1-deficient $40 \mathrm{~S}$ subunits in vitro. We first purified $\triangle R A C K 140 \mathrm{~S}$ ribosomal subunits and determined that they bound fluorescently labeled HCV IRES with a similar efficiency to wild-type subunits and were competent in $\mathrm{Mg}^{2+}$-driven 80S-IRES formation (Supplemental Fig. 8A,B). These analyses further validated the stability of RACK1-deficient ribosomes and implied that any requirement for RACK1 in HCV IRES activity is independent of mRNA recruitment (Majzoub et al. 2014). Recombinant RACK1 incorporated into $\triangle \mathrm{RACK} 1$ 40S subunits, and it did so far more efficiently than to wildtype 40S subunits (Supplemental Fig. 8C,D). The small amount of RACK1 that incorporated into wild-type ribosomes ( $20 \%$ relative to the RACK1-deficient subunits), which presumably have native RACK1 present, likely reflects a small population that lacked RACK1 or exchange of the native protein with the labeled recombinant version over the time course of the experiment. As hypothesized, the D107Y mutant RACK1 failed to incorporate into WT and RACK1-deficient 40S subunits, whereas S278E RACK1 incorporated at similar levels as the wild-type protein into both ribosomes (Supplemental Fig. 8D). Although Asc1p incorporated into $\triangle R A C K 140 S$ subunits, it failed to incorporate into wild-type ribosomes, supporting a loweraffinity than RACK1 for the human ribosome. Furthermore, in vitro reconstituted 40S-RACK1-ybbR ribosomal subunits were competent to form 805 complexes on the HCV IRES without notable RACK1 dissociation (Supplemental Fig. $8 \mathrm{E})$, contrasting a previous structural study of the complex in which $\sim 50 \%$ of particles lacked RACK1 density (Boehringer et al. 2005).

To confirm that recombinant RACK1 incorporates into the native RACK1 binding site, we examined in vitro reconstituted $40 \mathrm{~S}$ ribosomal subunits bound to labeled HCV IRES using single-molecule FRET. In complex with HCV IRES(C44-Cy5), in vitro reconstituted 40S-RACK1-ybbR subunits yielded a broad smFRET efficiency distribution with a mean centered at $\sim 0.31$ (Supplemental Fig. 8F,G). This was remarkably similar to the mean intensity observed with native 40S-RACK1-ybbR subunits ( 0.28) (Supplemental Fig. 4I). However, the smFRET efficiency distribution of the reconstituted complex had a broader standard deviation than that of native 40S-RACK1-ybbR ( 0.30 versus $\sim 0.21)$, potentially resulting from multiple, heterogeneous FRET states that are difficult to distinguish. These modest differences between native and in vitro reconstituted 40S-RACK1-ybbR subunits may represent differences in post-translational modifications of RACK1 (e.g., amino-terminal acetylation; Van De Waterbeemd et al. 2018) or modifications of other RPs as discussed above (Supplemental Fig. 3D). We also found that human $40 S$ subunits containing Asc1p-ybbR yielded an smFRET distribution similar to both in vitro reconstituted and native 40S-RACK1-ybbR subunits, albeit with a small population of high FRET states (mean 1.00) (Supplemental Fig. 8F, $\mathrm{G})$. Of note, following reconstitution, Asc1p had to be included in the TIRFM imaging buffer to facilitate observation of enough smFRET instances for analysis, which was not required for human RACK1 and preliminarily suggested that Asc1p has a shorter residence time on the human $40 \mathrm{~S}$ subunit. Thus, our findings demonstrate that recombinant RACK1-ybbR incorporated into its native binding site on the ribosome in vitro and the reconstituted ribosomes behave similarly to those assembled in cells.

Enabled by our reconstituted system, we next measured the kinetics of RACK 1 association to $\triangle R A C K 1$ ribosomes using real-time smFRET analyses in ZMWs. We immobilized preformed complexes of the HCV IRES, labeled at C44 with Cy3.5, and $\triangle R A C K 1$ 40S ribosomal subunits in ZMWs (Fig. 4A). RACK1 association with the 40S-IRES complex was observed via appearance of smFRET (Fig. 4B; Supplemental Fig. 9A). As predicted for a single-step bimolecular association, RACK1 displayed concentrationdependent association times (Fig. 4C; Supplemental Fig. 9B). After fitting data from the 15, 25, 50, 75, and 100 nM RACK1 deliveries with double-exponential functions, we found that both the rates and amplitudes were concentration dependent (Fig. 4D; Supplemental Fig. 9C-E). The fast second-order rate constant was approximately $2 \mu \mathrm{M}^{-1}$ $\mathrm{sec}^{-1}$ at $20^{\circ} \mathrm{C}$ (Fig. 4D), which increased linearly with temperature in a range from $20^{\circ} \mathrm{C}$ to $37^{\circ} \mathrm{C}$ (see Materials and Methods for more details; Fig. 4E; Supplemental Fig. 9E-G). The slow second-order rate constant was approximately 20-fold slower $\left(\sim 0.08 \mu \mathrm{M}^{-1} \mathrm{sec}^{-1}\right)$ and plateaued at $30^{\circ} \mathrm{C}$ (Supplemental Fig. 9C-E). The slow phase might represent a sub-population of RACK1-deficient 40S subunits that inhibits RACK1 reincorporation, perhaps due to a post-transcriptional modification on or near the RACK1 binding site, a conformational rearrangement of the 40SIRES complex, and/or a missing factor that orients the ribosome in a RACK1-accessible conformation. However, the slow phase could instead represent an experimental artifact arising from a source such as nonuniform mixing across the ZMW chip upon delivery of RACK1-ybbR (Chen et al. 2014). Regardless, the fast association rate we observed for RACK 1 incorporation is similar to association rates observed for protein-protein (median $\approx 6.6 \mu \mathrm{M}^{-1} \mathrm{sec}^{-1}$ ) and protein-RNA (median $\approx 6.3 \mu \mathrm{M}^{-1} \mathrm{sec}^{-1}$ ) interactions (Schreiber 2002; Gleitsman et al. 2017), and it provides a useful baseline rate for incorporation of a core RP into mature human ribosomes.

To test the role of RACK1 sequence on ribosomal association and dissociation kinetics, we probed binding of 
RACK1 mutants using single-molecule FRET. We first delivered the RACK1 mutant (D107Y) to immobilized $\triangle R A C K 1$ 40S-IRES complexes in ZMWs as above. Consistent with a weaker interaction, the D107Y substitution reduced the rate of RACK1 association (Supplemental Fig. 9H); however, due to the reduced stability we observed in vitro (Supplemental Fig. 6), we suspect that this effect could be due to an overestimation of the folded and active RACK1 concentration. We therefore examined yeast Asc1p association with the human ribosome given its in vitro stability and our prior results suggesting a dynamic ribosome interaction. Upon its delivery to immobilized $\triangle$ RACK1 40S-IRES complexes, the rate of Asc1p association was dependent on its concentration and temperature (Supplemental Fig. 10A-C). The observed fast association rate for Asc1p at $75 \mathrm{nM}\left(\sim 0.2 \mathrm{sec}^{-1}\right.$ at $\left.20^{\circ} \mathrm{C}\right)$ was similar to the observed RACK 1 association rate $\left(\sim 0.2 \mathrm{sec}^{-1}\right)$ in identical conditions (Supplemental Fig. 10B), as estimated via double-exponential functions (Supplemental Figs. 9E, 10C). However, in contrast to RACK1, we observed multiple Asc1p binding events separated by as little as 1-3 min on a single 40S-IRES complex, which increased with Asc1p concentration and reaction temperature (Fig. 4F; Supplemental Fig. 10D-F). Thus, our real-time data suggest that perturbing the RACK1-ribosome interface alters the stability of the interaction.

We next applied single-molecule and bulk approaches to determine the rate of dissociation of wild-type and mutant RACK1 from ribosomes. Wild-type RACK1 and Asc1p residence times on the 40S-IRES complex, defined as the duration of smFRET events, were both concentration-independent (Supplemental Fig. 11A-C) and dependent on the power of the excitation laser (Supplemental Fig. 11D). Thus, our single-molecule residence time measurements were limited by photobleaching of the dyes, suggesting that they underestimated the lifetime of RACK1-ribosome interactions. To overcome this obstacle, we applied an ensemble approach using native gel electrophoresis. We incubated native 40S-RACK1-ybbR-Cy5 ribosomal subunits with a 20-fold excess of recombinant, unlabeled RACK1-ybbR and quantified the departure of RACK 1-ybbR-Cy5 from the ribosome by resolving 40S subunits on a native gel. In this assay, ribosome binding of the unlabeled competitor prevents reassociation of the labeled protein upon its dissociation from the ribosome, yielding a time-dependent decrease in fluorescence signal. After $24 \mathrm{~h}$ at $37^{\circ} \mathrm{C}$, nearly all of the Cy5 fluorescent signal was lost upon competition with excess RACK1-ybbR (Fig. 4G). Furthermore, there was near-complete exchange of RACK1 upon competition with 10-fold excess RACK1ybbR-Cy3, indicating that the RACK1 binding site and ribosomal subunits remain intact throughout the experimental window. In contrast, we observed minimal exchange of RACK 1 at $20^{\circ} \mathrm{C}$ or upon competition with 20 -fold excess Asc1p at both temperatures. We therefore measured the half-life of RACK 1 on the ribosome at $37^{\circ} \mathrm{C}$, which we determined to be $\sim 15 \mathrm{~h}$ using this bulk exchange assay (Fig. $4 \mathrm{H}$; Supplemental Fig. 11E). Together with the observed fast association rate estimated from the $37^{\circ} \mathrm{C}$ single-molecule experiments, we estimated an equilibrium dissociation constant of $\sim 10$ pM for the RACK1-40S interaction. These results suggest that RACK1 will be stably associated with the ribosome for well over the timeframe of translation in the cell, a process that is typically completed within a few minutes.

\section{DISCUSSION}

Single-molecule fluorescence strategies are powerful approaches to examine the inherent dynamics of protein synthesis. In this work, we establish RACK1 as a new location to label the human ribosome site-specifically with fluorescent dyes via a compact peptide tag and SFP synthase (Yin et al. 2006). By leveraging the proximity of HCV IRES domain II to RACK1 within the 40S-IRES complex, we applied a smFRET signal to examine the kinetics of the RACK1-ribosome interaction. This integration of biochemical, biophysical, and cell-based approaches revealed the remarkable stability of RACK1 on the ribosome. Unlike prokaryotic systems for which ribosome assembly has been reconstituted (Traub and Nomura 1968; Nierhaus and Dohme 1974), such kinetic parameters of RP-ribosome interactions have remained elusive in humans.

Our initial goal was to engineer human ribosomes for improved labeling with fluorescent dyes amenable to single-molecule analysis. RACK1 was an ideal candidate, as it is dispensable for growth in select cell lines, located between the mRNA entry and exit channels, and proximal to binding sites of translation-related factors and viral IRESs. We therefore fused the 11 amino acid ybbR tag onto RACK1, which is among a small group of peptide tags used to label ribosomes in other species (Kaiser et al. 2011; Wang et al. 2012). However, such a short tag has yet to be applied to human ribosomes, and RACK1 is linked to a myriad of translation-related cellular processes. We therefore characterized RACK1-ybbR tagged 40S subunits using orthogonal lines of experiments in cells, and with bulk and single-molecule analyses to ensure their functionality. We found that ribosomes with RACK1-ybbR are functional in cells, biochemically intact, active in simple functional assays, and amenable to single-molecule assays on multiple platforms. In tandem with the segmental-labeling strategy of the IRES, they yielded an unambiguous smFRET signal for the presence of RACK1 within the 40SIRES complex and enabled us to refine our previous analyses on the dynamics of HCV IRES domain II within the 40S-IRES complex. We also demonstrate their amenability to real-time measurements in ZMWs with complete translation systems. Together, this work highlights the utility of compact labeling schemes for large RNAs and 
ribonucleoprotein complexes in single-molecule assays. It also illustrates that ybbR and other small peptide tags are prime candidates for tagging human RPs at their endogenous genomic loci, expanding the candidates for fluorescent labeling to include essential RPs.

Our in vitro experiments collectively demonstrate that RACK 1 is a rigid and stable component of the human ribosome. Motivated by the rarity of information on the biochemistry of RP-deficient ribosomes and the rates of in vitro RP exchange (Kossinova et al. 2008; May et al. 2012), we leveraged the smFRET signal described above with $\triangle R A C K 140 S$ subunits and RACK1-ybbR to monitor RACK1 binding directly to the ribosome. We showed that RACK1-deficient $40 S$ subunits are functional in simple biochemical assays and nearly identical in composition to wildtype ribosomes. Recombinant RACK1 specifically and unambiguously reincorporates into human $\triangle R A C K 1$ ribosomes at the expected location and we observe limited conformational dynamics. The fast second-order rate constant for RACK 1 incorporation is $\sim 4 \mu \mathrm{M}^{-1} \mathrm{~s}^{-1}$ at $37^{\circ} \mathrm{C}$, similar to that of Asc1p incorporation ( $k_{\text {on }} \approx 2 \mu \mathrm{M}^{-1} \mathrm{~s}^{-1}$ at $37^{\circ} \mathrm{C}$ ), which served as our best available proxy for a stable RACK1 mutant. Using a native gel shift assay, we found that RACK1 has a long half-life on the human ribosome in vitro $\left(t_{1 / 2} \approx 15 \mathrm{~h}\right)$, consistent with the expectation from most structural analyses. Substitutions along the RACK1-ribosome interface, as demonstrated by the use of the distantly related Asc1p, led to multiple dissociation and reassociation events on the $40 \mathrm{~S}$ subunit over the short time window of our single-molecule experiments. Thus, the high-affinity RACK1-ribosome interaction $\left(K_{D} \approx 10\right.$ $\mathrm{pM})$ is specified by the slow rate of RACK1 dissociation that is likely mediated by the extensive interface $(\sim 1800$ $\AA^{2}$ ) between RACK 1 and the ribosome, which includes contacts with three RPs and 18S rRNA (Sengupta et al. 2004; Nielsen et al. 2017).

Both in our single-molecule assays and in cells, the ribosome is often assumed to have infinite stability over its lifetime. Recent cellular studies have challenged this paradigm and have proposed that variations in the composition of the ribosome can yield specialized functions (Gilbert 2011; Xue and Barna 2012). To overcome the intrinsic stability of the RACK1-ribosome interaction that we observed, however, regulatory control via RACK1 ribosome occupancy would require hours for its stochastic departure from the ribosome or active mechanisms to release RACK1. Indeed, our findings are consistent with the possibility that the ribosome-bound and small pool of free RACK1 can exchange stochastically over the lifetime of a ribosome $\left(t_{1 / 2} \approx 5-7 d\right)$ (Dice and Schimke 1972; Nikolov et al. 1987; Defoiche et al. 2009; Mathis et al. 2017). Such exchange has been proposed for other RPs and may take place during viral infections in bacteria (Mizuno et al. 2019) and neuronal functions of mammals (Shigeoka et al. 2018). On the other hand, rapid changes to mature ribosomes could be achieved through the activated release of RACK1, or another RP, perhaps triggered by covalent modifications or other ribosome rearrangements. The RP eS10 may be an example of such a phenomenon, as it has been observed at sub-stoichiometric levels in the human ribosome (Shi et al. 2017; Van De Waterbeemd et al. 2018) and is a target for regulatory ubiquitination (Sundaramoorthy et al. 2017; Juszkiewicz et al. 2018). Our in vitro findings therefore provide an initial kinetic benchmark for the stability of an integral RP on mature human ribosomes, lending biochemical insight for complementary cellular investigations on the biological consequences and timescales of RP exchange.

The results presented here establish RACK1 as an advantageous location to install a compact fluorescent label on the human ribosome. We demonstrate the utility of this labeling position by defining baseline kinetic parameters for RACK1 association with the ribosome, revealing the remarkable stability of the interaction. We therefore expand the toolkit available for single-molecule studies required to reveal the kinetics that govern human translation and its regulation (Sokabe and Fraser 2018), and provide a biochemical benchmark for the flux of RPs on and off the mature ribosome.

\section{MATERIALS AND METHODS}

\section{Molecular cloning}

To isolate human RACK1 cDNA for cloning, total RNA from HeLa cells was extracted using TRIzol (ThermoFisher, cat.\# 15596026), reverse transcribed and amplified with gene-specific primers, transformed into TOP10 cells, and validated by Sanger sequencing. To make the RACK1-ybbR lentiviral expression construct, RACK1-ybbR was amplified and inserted into pENTR/D-TOPO (ThermoFisher) and then cloned into the lentivirus expression plasmid pLenti CMV Puro DEST (w118-1) (Addgene) by Gateway cloning (ThermoFisher) and validated by sequencing. The open-reading frames (ORFs) for RACK1 proteins were inserted into a pET28c-6xHis-MBP bacterial recombinant expression plasmid backbone downstream from MBP using a construct derived from a human elF1A expression construct (Fraser et al. 2007). The ORF from human RACK1 was subcloned from the lentivirus expression construct, the ORF for $P$. falciparum RACK1 (PfRACK1) was subcloned from $P$. falciparum asexual stage cDNA from the D10 strain (a gift from Michael Boucher, Ellen Yeh laboratory), and the ORF for $S$. cerevisiae Asc1p was subcloned from a cloned cDNA construct purchased from Genscript (ORF clone OSi04112D). At the 3' end of each construct was sequence encoding for the ybbR peptide tag and a stop codon (GATTCTCTTGAATTTATTGCTAGTAAGCTTGCGTAG). We refer to the proteins encoded by these plasmids as 6xHis-MBP-RACK1/ Asc1p-ybbR fusion proteins. The D107Y, R38D/K40E, and S278E amino acid substitutions were introduced into human RACK1 using the QuickChange II XL site-directed mutagenesis kit (Roche). All plasmids are available upon request. 


\section{Cell growth}

HAP1 cells were grown at $37^{\circ} \mathrm{C}$ with $5 \% \mathrm{CO}_{2}$ in Iscove's Modified Dulbecco's medium (IMDM) (Gibco, cat.\# sh30228) supplemented with $10 \%(\mathrm{v} / \mathrm{v})$ fetal bovine serum, $2 \mathrm{mM}$ L-glutamine (Gibco), and $1 \mathrm{X}$ penicillin/streptomycin (Gibco). As indicated, wild-type and $\triangle$ RACK1 (clone E3-A5) HAP1 cells were used in our studies (Carette et al. 2011; Jha et al. 2017).

\section{Lentiviral transductions}

Lentivirus packaging was conducted either at the Neuroscience Gene Vector and Virus Core of Stanford University or performed in-house using pLenti constructs by cotransfection with $\triangle \mathrm{VPR}$, VSV-G, and pAdVAntage packaging plasmids into HEK293FT cells using FuGENE HD (Promega) (Campeau et al. 2009). Cells were transduced with lentivirus-containing media $24 \mathrm{~h}$ after seeding in six-well plates at 250,000 cells per well. Lentivirus-containing media was replaced with fresh media after $24 \mathrm{~h}$, and after an additional $24 \mathrm{~h}$, transduced cells were selected by the addition of $1 \mu \mathrm{g} / \mathrm{mL}$ puromycin. Following $5 \mathrm{~d}$ under puromycin selection, surviving cells were expanded in culture for characterization and ribosome purifications.

\section{Polysome profiling}

HAP1 cells were grown by routine passaging and cells were brought to $~ 80 \%$ confluence in $150-\mathrm{mm}$ culture dishes, receiving fresh IMDM media 4-6 $\mathrm{h}$ before harvesting. Immediately before harvest, $100 \mu \mathrm{g} / \mathrm{mL}$ cycloheximide $(\mathrm{CHX})$ was added to media, and cells were incubated for $3 \mathrm{~min}$ at $37^{\circ} \mathrm{C}$. Media was removed by aspiration, adherent cells were washed twice with ice-cold PBS (containing $100 \mu \mathrm{g} / \mathrm{mL} \mathrm{CHX}$ ). PBS was aspirated from cells, which were subsequently dissociated from plates by scraping and transferred to Eppendorf tubes in residual PBS. An equal volume of $2 X$ cell lysis buffer $(30 \mathrm{mM}$ Tris- $\mathrm{HCl}$ pH 7.5, $150 \mathrm{mM} \mathrm{NaCl}$, $2 \%$ Triton X-100, $10 \mathrm{mM} \mathrm{MgCl} 2,2 \mathrm{mg} / \mathrm{mL}$ heparin, $0.2 \mathrm{mg} / \mathrm{mL}$ $\mathrm{CHX}$, and $2 \mathrm{mM}$ DTT) was mixed with cell suspensions, and lysis proceeded for $10 \mathrm{~min}$ on ice. Lysate was clarified to remove nuclei at $8400 \mathrm{~g}$ for $5 \mathrm{~min}$ at $4^{\circ} \mathrm{C}$ with a microcentrifuge, and lysates were measured with a nanodrop to normalize gradient inputs by absorbance at $260 \mathrm{~nm}$. Using $14 \times 89 \mathrm{~mm}$ thin-wall polypropylene tubes (Beckman Coulter ref. 331372), 10\%-60\% sucrose gradients were prepared in $20 \mathrm{mM}$ Tris- $\mathrm{HCl} \mathrm{pH} 7.5,150 \mathrm{mM} \mathrm{NaCl}, 5 \mathrm{mM}$ $\mathrm{MgCl}_{2}, 0.1 \mathrm{mg} / \mathrm{mL} \mathrm{CHX}$, and $1 \mathrm{mM}$ DTT, and linearized using a BioComp 107 Gradient Master. Post-nuclear lysate samples from a single $150-\mathrm{mm}$ dish ( $500 \mu \mathrm{L}$ of $\sim 1000 \mathrm{ng} / \mu \mathrm{L}$ RNA) was loaded onto each prechilled sucrose gradient and centrifuged at $150,000 \mathrm{~g}$ (35,000 rpm) using a SW41 Ti rotor for $2 \mathrm{~h} 45 \mathrm{~min}$ at $4^{\circ} \mathrm{C}$. Gradients were fractionated with a Brandel gradient fractionation system using a $5 \mathrm{~mm}$ UV cell detector, pumping at $0.75 \mathrm{~mL}$ per minute, and collecting fractions across the length of the gradient. Protein was extracted from each $0.75 \mathrm{~mL}$ fraction by methanol extraction. Briefly, $0.1 \mathrm{~mL}$ of each fraction was mixed with $0.4 \mathrm{~mL}$ methanol, vortexed, and spun for $10 \mathrm{sec}$ at $9000 \mathrm{~g}$ in a microcentrifuge. To each sample, $0.1 \mathrm{~mL}$ chloroform was added, followed by additional vortexing. Next, $0.3 \mathrm{~mL}$ nanopore $\mathrm{H}_{2} \mathrm{O}$ was added to each fraction with vortexing for phase separation. The upper phase was discarded, and $0.3 \mathrm{~mL}$ was added to the low- er phase with more vortexing. The protein was then pelleted by centrifuging at max speed in a microcentrifuge for $2 \mathrm{~min}$, from which the supernatant was removed, and the pellet was further dried using a SpeedVac. Dried protein pellets were resuspended in $0.01 \mathrm{~mL} 8 \mathrm{M}$ Urea/ $100 \mathrm{mM}$ Tris- $\mathrm{HCl} \mathrm{pH}$ 8.0. Solubilized proteins were then used for SDS-PAGE and western blotting.

\section{Proliferation assay}

Proliferation assays were performed as described previously (Johnson et al. 2018). Briefly, wild-type, $\triangle R A C K 1$, and $\triangle R A C K 1$ + RACK1-ybbR HAP1 cells were dissociated from culture plates with trypsin and counted for live cells by trypan blue. Cells were then seeded into 96-well plates at 10,000 live cells/well with 10 replicates per cell line, assaying over $4 \mathrm{~d}$ of growth using the Vybrant MTT Cell Proliferation Assay Kit (ThermoFisher). Absorbance values at $570 \mathrm{~nm}$ were determined using a Synergy Neo2 instrument (BioTek).

\section{Immunoblotting}

Western blotting was performed as described previously (Johnson et al. 2018). When reprobing blots, HRP-conjugated secondary antibodies were either inactivated by incubation with sodium azide in $5 \%$ skim milk/TBST or stripped with Restore Stripping Buffer (ThermoFisher). The following antibodies were used in this study: anti-RACK1 (Cell Signaling, ref. 4716S, 1:1000), anti-RACK1 (Santa Cruz, ref. 17754, 1:500), RPL5 (Genetex, ref. 101821, 1:1000), uS10/RPS20 (abcam, ref. 133776, 1:1000), eS10/RPS10 (Genetex, ref. 101836, 1:1000), uS5/RPS2 (Santa Cruz, ref. 130399, 1:500), and uS3/RPS3 (Bethyl, ref. 303-840A, 1:1000).

\section{Ribosome purifications}

$40 S$ and 605 ribosomal subunits from wild-type, $\triangle R A C K 1$, and $\triangle R A C K 1+R A C K 1-y b b R$ HAP1 cells were purified as described previously with a few optimizations (Fuchs et al. 2015). A total of 20-40 × 150-mm culture dishes were grown to 80\% confluency. Media was removed, cells were washed with ice-cold PBS, and PBS was removed via aspiration. In the residual PBS, cells were scraped to release them from the dish, combined into a $15 \mathrm{~mL}$ culture tube, and pelleted by centrifugation at $1000 \mathrm{~g}$ for $10 \mathrm{~min}$ in an Eppendorf $5810 \mathrm{R}$ centrifuge equipped with a swinging bucket rotor. Cell pellets were resuspended in ice-cold PBS and repelleted via centrifugation to wash. PBS was removed via aspiration, and cell pellets were resuspended in an equal volume of fresh, ice-cold PBS (typically 1-2 mL). An equal volume of $2 X$ lysis buffer (30 mM Tris- $\mathrm{HCl} \mathrm{pH} 7.5,300 \mathrm{mM} \mathrm{NaCl}, 20 \mathrm{mM} \mathrm{MgCl}_{2}, 2 \%$ (v/v) Triton-X 100, $4 \mathrm{mM}$ DTT, $2 \mathrm{mg} / \mathrm{mL}$ heparin, and $1 \mathrm{X}$ CoMplete Mini protease inhibitor cocktail [Roche]) was added, cells were mixed gently by multiple inversions of the culture tube, and cells were incubated on ice for 10 min to complete lysis. Cell lysates were cleared of debris and nuclei via centrifugation at $42,000 \mathrm{~g}(10,000 \mathrm{rpm})$ at $4^{\circ} \mathrm{C}$ for $10 \mathrm{~min}$ in a Fiberlite $\mathrm{F} 21$ rotor. The supernatant was layered directly onto a high-salt sucrose cushion (20 mM Tris- $\mathrm{HCl}$ pH 7.5, $500 \mathrm{mM} \mathrm{KCl,} \mathrm{30 \%} \mathrm{(v/v)} \mathrm{sucrose,}$ $10 \mathrm{mM} \mathrm{MgCl}_{2}$. $0.1 \mathrm{mM}$ EDTA pH 8.0, and $2 \mathrm{mM} \mathrm{DTT}$ ). Ribosomes 
were pelleted via centrifugation at $63,000 \mathrm{~g}$ for $16-18 \mathrm{~h}$ at $4^{\circ} \mathrm{C}$ using a Type 80 Ti rotor (Beckman Coulter). Ribosome pellets were dissolved in resuspension buffer $(20 \mathrm{mM}$ Tris- $\mathrm{HCl} \mathrm{pH} \mathrm{7.5,500} \mathrm{mM}$ $\mathrm{KCl}, 7.5 \%[\mathrm{v} / \mathrm{v}]$ sucrose, $2 \mathrm{mM} \mathrm{MgCl}_{2}, 75 \mathrm{mM} \mathrm{NH}_{4} \mathrm{Cl}, 2 \mathrm{mM}$ puromycin, and 2 mM DTT) by gentle pipetting. To complete resolubilization and splitting of the ribosomal subunits, ribosomes were incubated at $4^{\circ} \mathrm{C}$ for $1 \mathrm{~h}$ followed by an incubation at $37^{\circ} \mathrm{C}$ for $1.5 \mathrm{~h}$. To isolate $40 \mathrm{~S}$ and $60 \mathrm{~S}$ ribosomal subunits, the solution was layered directly onto a prechilled linear 10\%-30\% sucrose gradient (with $20 \mathrm{mM}$ Tris- $\mathrm{HCl} \mathrm{pH} 7.5,500 \mathrm{mM} \mathrm{KCl}, 6 \mathrm{mM}$ $\mathrm{MgCl}_{2}$ ) in $25 \times 89 \mathrm{~mm}$ polypropylene centrifuge tubes (Beckman Coulter, ref. 326823) prepared using the BioComp 107 Gradient Master. Gradients were centrifuged at 49,123g for $16 \mathrm{~h}$ at $4^{\circ} \mathrm{C}$ using an SW32Ti rotor. Gradients were fractionated with a Brandel gradient fractionation system using a $1 \mathrm{~mm}$ UV cell detector, pumping at $1.5 \mathrm{~mL}$ per minute, and collecting $0.75 \mathrm{~mL}$ fractions across the length of the gradient. Fractions containing 405 and 605 ribosomal subunits as identified via absorption at $254 \mathrm{nM}$ were pelleted via centrifugation at $63,000 \mathrm{~g}$ for $20 \mathrm{~h}$ at $4^{\circ} \mathrm{C}$ using a Type $80 \mathrm{Ti}$ rotor (Beckman Coulter). Ribosomal subunits were resuspended in storage buffer $[30 \mathrm{mM}$ HEPES-KOH pH 7.4, $100 \mathrm{mM} \mathrm{KOAc,} 5 \mathrm{mM} \mathrm{Mg}(\mathrm{OAc})_{2}, 6 \%(\mathrm{v} / \mathrm{v})$ sucrose, and $2 \mathrm{mM}$ DTT], aliquoted, flash frozen in liquid $\mathrm{N}_{2}$, and stored at $-80^{\circ} \mathrm{C}$. Ribosome concentrations and labeling efficiencies were determined by measuring absorbance at $260 \mathrm{~nm}$ (total ribosome concentration) and at 548 or $646 \mathrm{nM}$ (Cy3 or Cy5 dyes, labeled ribosome concentration) using a NanoDrop and the appropriate extinction coefficients. Ribosomal subunits were characterized by SDS-PAGE (Bio-Rad Any kD precast gels), the Pierce Silver Stain Kit (ThermoFisher), western blotting, and mass-mapping with the Stanford PAN facility.

\section{SFP synthase labeling of ybbR peptides}

SFP synthase was expressed recombinantly in bacteria using the pET29-Sfp construct (a gift from Jun Yin at Georgia State University) (Yin et al. 2006). Protein expression was performed as described, and protein was subsequently used to catalyze ybbR labeling reactions. Sulfo-Cyanine3 (cat. \# 11380) and Sulfo-Cyanine5-maleimide (cat. \# 13380) were purchased from Lumiprobe. Coenzyme A trilithium salt (CoA) was purchased from Sigma-Aldrich (cat.\# C3019). CoA was reacted with maleimide-dyes as described, and CoA-dyes were purified using a $5 \%-50 \%$ gradient of acetonitrile in water with $0.1 \%$ TFA using an HPLC equipped with a C18 column (Yin et al. 2006). Successful synthesis and purification of CoA-dye products was verified by LC-MS analysis. After confirming the published synthesis and purification scheme, we instead used the crude CoA-dye reactions without HPLC purification, by quenching excess maleimide with DTT and directly labeling ybbR-tagged proteins with SFP synthase.

$40 S$ ribosomal subunits containing RACK1-ybbR were fluorescently labeled with Cy3 or Cy 5 by incubating 40 S subunits with 2-4 molar excess SFP synthase and CoA-Cyanine dyes at $37^{\circ} \mathrm{C}$ for $2 \mathrm{~h}$ in ybbR-labeling buffer $(50 \mathrm{mM}$ HEPES-KOH $\mathrm{pH} 7.5$, $100 \mathrm{mM} \mathrm{NaCl}, 10 \mathrm{mM} \mathrm{MgCl} 2,10 \%$ [v/v] glycerol, and $1 \mathrm{mM}$ DTT). To remove free dye and SFP synthase, labeled $40 \mathrm{~S}$ subunits were layered onto a low-salt sucrose cushion [30 mM HEPES-KOH $\mathrm{pH}$ 7.5, $100 \mathrm{mM} \mathrm{KOAc}, 0.5 \mathrm{M}$ sucrose, $5 \mathrm{mM} \mathrm{Mg(OAc)})_{2}$, and 2
$\mathrm{mM} \mathrm{DTT}]$, and centrifuged at $287,000 \mathrm{~g}(90,000 \mathrm{rpm})$ for $1 \mathrm{~h}$ at $4{ }^{\circ} \mathrm{C}$ in a TLA100.2 rotor in $11 \times 34 \mathrm{~mm}$ thick-wall polycarbonate ultracentrifuge tubes (Beckman, ref. 343788). Ribosome pellets were washed once and subsequently resuspended with ribosome storage buffer, aliquoted, flash frozen in liquid $\mathrm{N}_{2}$, and stored at $-80^{\circ} \mathrm{C}$. Recombinant proteins were labeled with cyanine dyes by incubating $10 \mu \mathrm{M}$ 6xHis-MBP-RACK1-ybbR proteins with 2 $\mu \mathrm{M}$ SFP synthase and $15 \mu \mathrm{M}$ CoA-Cy $3 / 5$ dyes at $37^{\circ} \mathrm{C}$ for $2 \mathrm{~h}$. Free dye was removed via purification over 10DG-desalting columns (Bio-Rad, cat.\# 7322010) equilibrated in TEV buffer (20 $\mathrm{mM}$ Tris- $\mathrm{HCl} \mathrm{pH} \mathrm{8.0,150} \mathrm{mM} \mathrm{NaCl,10 \%} \mathrm{[v/v]} \mathrm{glycerol,} 10$ mM imidazole, and $5 \mathrm{mM} \beta$-mercaptoethanol). Dye-labeled proteins and ribosomes were characterized as indicated by SDS-PAGE (BioRad Any kD precast gels), fluorescent scanning using a Typhoon instrument, the Pierce Silver Stain Kit (ThermoFisher), western blotting, and mass-mapping with the Stanford PAN facility. Protein concentrations and labeling efficiencies were determined by measuring absorbance at $280 \mathrm{~nm}$ (total protein concentration) and at 548 or $646 \mathrm{nM}$ (Cy3 or Cy5 dye, labeled protein concentration) using a NanoDrop and the appropriate extinction coefficients.

\section{RACK1 recombinant protein expression and purification}

Recombinant 6xHis-MBP-RACK1-ybbR fusion proteins were expressed and purified from E. coli BL21(DE3) cells. Two to four liters of cells were grown at $37^{\circ} \mathrm{C}$ in LB supplemented with 50 $\mu \mathrm{g} / \mathrm{mL}$ kanamycin to $\mathrm{OD}_{600}$ of 0.5 , and cells were rapidly cooled on ice. Expression of the fusion proteins was induced by addition of $0.5 \mathrm{mM} \mathrm{IPTG}$, and cells were maintained in a shaking incubator for $16 \mathrm{~h}$ at $17^{\circ} \mathrm{C}$. Cells were harvested by centrifugation at $5000 \mathrm{~g}$ for $10 \mathrm{~min}$ at $4^{\circ} \mathrm{C}$ in a Fiberlite F9 rotor.

Cells were lysed by sonication in lysis buffer $(20 \mathrm{mM}$ Tris- $\mathrm{HCl}$ $\mathrm{pH}$ 8.0, $300 \mathrm{mM} \mathrm{NaCl}, 10 \%$ [v/v] glycerol, $10 \mathrm{mM}$ imidazole, and $5 \mathrm{mM} \beta$-mercaptoethanol), and lysates were cleared by centrifugation at $38,000 \mathrm{~g}$ for $10 \mathrm{~min}$ at $4^{\circ} \mathrm{C}$ in a Fiberlite F21 rotor followed by filtration through a $0.22 \mu \mathrm{m}$ syringe filter. Clarified lysate was loaded onto a Ni-NTA gravity flow column equilibrated in lysis buffer, washed with 20 column volumes (CV) of lysis buffer, $20 \mathrm{CV}$ of wash buffer $(20 \mathrm{mM}$ Tris- $\mathrm{HCl} \mathrm{pH} 8.0,1 \mathrm{M} \mathrm{NaCl}, 10 \%$ [v/v] glycerol, $25 \mathrm{mM}$ imidazole, and $5 \mathrm{mM} \beta$-mercaptoethanol), and $10 \mathrm{CV}$ of lysis buffer. Recombinant proteins were eluted with six sequential $\mathrm{CV}$ of elution buffer $(20 \mathrm{mM}$ Tris- $\mathrm{HCl} \mathrm{pH}$ 8.0, $300 \mathrm{mM} \mathrm{NaCl}, 10 \%$ [v/v] glycerol, $250 \mathrm{mM}$ imidazole, and $5 \mathrm{mM}$ $\beta$-mercaptoethanol), and fractions with recombinant protein as identified by SDS-PAGE analyses were dialyzed overnight at $4^{\circ} \mathrm{C}$ into ybbR-labeling buffer $(50 \mathrm{mM}$ HEPES-KOH $\mathrm{pH} 7.5$, $100 \mathrm{mM} \mathrm{NaCl}, 10 \mathrm{mM} \mathrm{MgCl}_{2}, 10 \%$ [v/v] glycerol, and $1 \mathrm{mM}$ DTT) or TEV Buffer (20 mM Tris- $\mathrm{HCl}$ pH 8.0, $150 \mathrm{mM} \mathrm{NaCl}, 10 \%$ [v/v] glycerol, $10 \mathrm{mM}$ imidazole, and $5 \mathrm{mM} \beta$-mercaptoethanol).

Fluorescently labeled and unlabeled proteins were dialyzed overnight in the dark at $4^{\circ} \mathrm{C}$ into TEV buffer in the presence of 1-1.5 mg of TEV protease. To separate 6xHis-tagged proteins from RACK1-ybbR(Cy3/5), the proteins were passed through a second Ni-NTA gravity column equilibrated in TEV buffer to capture 6xHis-MBP, TEV protease, and SFP synthase. Flow-through containing RACK1-ybbR(Cy3/5) was further purified using size exclusion chromatography using a Superdex 75 column $(23 \mathrm{~mL})$ 
equilibrated in SEC buffer (20 mM HEPES-KOH pH 7.5, 150 mM KOAc, 10\% [v/v] glycerol, and $1 \mathrm{mM} \mathrm{DTT)}$. Fractions containing RACK1-ybbR(Cy3/5) were concentrated using a $10 \mathrm{kD}$ MWCO Amicon Ultra centrifugal filter, aliquoted, flash frozen on liquid $\mathrm{N}_{2}$, and stored at $-80^{\circ} \mathrm{C}$. The concentration was determined via absorption at $280 \mathrm{~nm}$ using a nanodrop for total protein, and at 548 or $646 \mathrm{nM}$ for Cy3 or Cy5 labeled proteins, respectively. A concentration range of indicated recombinant proteins was analyzed by thermal melt assays in SEC buffer using SYPRO Orange (Molecular Probes, cat.\# S6651) using a Bio-Rad CFX96 Touch Real-Time PCR C1000 System (ramping from $4^{\circ} \mathrm{C}$ to $100^{\circ} \mathrm{C}$ at $1^{\circ} \mathrm{C}$ per minute).

\section{RNA transcription and fluorescent labeling}

For single-molecule experiments, HCV IRES RNA was produced and labeled with cyanine dyes as described previously (Johnson et al. 2018). Briefly, an acceptor RNA was transcribed in vitro by T7 with GMP-priming for segmental labeling. Synthetic RNA donor oligos with cyanine dyes installed terminally at C44 or internally at U56 (TriLink) were ligated to the acceptor RNA using T4 RNA ligase 1 (NEB) (Fig. 3; Supplemental Fig. 4). For TIRFM experiments, RNAs were labeled at C44 or U56 with Cyanine5, and for ZMW experiments, RNAs were labeled at C44 with Cyanine3 or Cyanine3.5.

For gel shift experiments, HCV IRES RNA that lacked the $3^{\prime}$ extension used in single-molecule experiments was transcribed in vitro using T7 polymerase, the RNA was extracted using phenol: chloroform:isoamyl alcohol, ethanol precipitated, and purified via size-exclusion chromatography on a Superdex 200 column $(23 \mathrm{~mL})$ equilibrated with $10 \mathrm{mM}$ Bis-Tris $\mathrm{pH} 7$ and $100 \mathrm{mM}$ $\mathrm{NaCl}$. RNA was concentrated using a $10 \mathrm{kD}$ MWCO Amicon Ultra centrifugal filter, aliquoted, flash frozen on liquid $N_{2}$, and stored at $-80^{\circ} \mathrm{C}$. The concentration was determined via absorption at $260 \mathrm{~nm}$ using a nanodrop.

To end label RNA with Cy 5 dye, purified RNA was incubated in $100 \mathrm{mM} \mathrm{NaOAc} \mathrm{pH} 5.5$ and $5 \mathrm{mM} \mathrm{KIO}_{4}$ for 30 min on ice in the dark. The reaction was quenched by addition of $10 \mathrm{mM}$ ethylene glycol and incubation for 5 min on ice in the dark. Oxidized RNA was ethanol precipitated, resuspended in $100 \mathrm{mM} \mathrm{NaOAc}$, and incubated with five- to 10-fold molar excess Cy5-hydrazide (Lumiprobe, cat. \# 13070) for $6 \mathrm{~h}$ at room temperature in the dark. Free dye was removed via purification over 10DG-desalting columns. Full-length, end-labeled RNA was purified by extraction from acrylamide gels following electrophoresis, ethanol precipitated, aliquoted, flash frozen, and stored at $-80^{\circ} \mathrm{C}$. The dye concentration was determined via absorption at $650 \mathrm{~nm}$ using a nanodrop spectrophotometer.

\section{Refolding of HCV IRES}

HCV IRES was diluted to 0.5 to $1 \mu \mathrm{M}$ in refolding buffer $(20 \mathrm{mM}$ cacodylate- $\mathrm{NaOH} \mathrm{pH} 7.0,100 \mathrm{mM} \mathrm{KCl}$, and $1 \mathrm{mM}$ EDTA pH 8), heated to $95^{\circ} \mathrm{C}$ for $2 \mathrm{~min}$, and slowly cooled to room temperature (more than $\sim 45 \mathrm{~min}$ ). For single-molecule experiments, a biotinylated DNA oligo that anneals to the $3^{\prime}$ end of the RNA on an artificial extension downstream from the IRES was included at twofold molar excess. Once cooled, $4 \mathrm{mM} \mathrm{MgCl}_{2}$ was added to quench the EDTA.

\section{Native gel electrophoresis}

Ribosomes and complexes of ribosomes and HCV IRES were analyzed using acrylamide/agarose composite gels as described previously (Johnson et al. 2018). Briefly, 2.75\% acrylamide (37.5:1), $0.5 \%$ Nusieve GTG agarose composite gels were prepared in the following buffer: $25 \mathrm{mM}$ Tris-OAc $\mathrm{pH} 7.5,4 \mathrm{mM}$ KOAc, 2 $\mathrm{mM} \mathrm{Mg}(\mathrm{OAc})_{2}, 0.5 \mathrm{mM}$ DTT, 2.5\% glycerol, 0.1\% (v/v) TEMED, and $0.1 \%(\mathrm{v} / \mathrm{v})$ fresh ammonium persulfate. The gels were cooled at $4^{\circ} \mathrm{C}$ for $20 \mathrm{~min}$ and allowed to further polymerize at room temperature for $2 \mathrm{~h}$. Gels were prerun in ice-cold running buffer [25 $\mathrm{mM}$ Tris-OAc $\mathrm{pH} 7.5,4 \mathrm{mM} \mathrm{KOAc}$, and $\left.2 \mathrm{mM} \mathrm{Mg}(\mathrm{OAC})_{2}\right]$ for $30-60 \mathrm{~min}$ at $4^{\circ} \mathrm{C}$. All native gel electrophoresis assays were repeated at least three times, and respective ribosome, protein, and RNA samples were derived from a single purification. For gel shift assays with HCV IRES, the indicated amounts of purified ribosomal subunits were incubated for $10 \mathrm{~min}$ at $37^{\circ} \mathrm{C}$ with RNA in ribosome assay buffer [ $30 \mathrm{nM}$ Cy5-labeled IRES in $30 \mathrm{mM}$ HEPES-KOH pH 7.4, $100 \mathrm{mM} \mathrm{KOAc}$, and $2 \mathrm{mM} \mathrm{Mg(OAc)}$ ]. For analysis of recombinant protein incorporation into purified ribosomal subunits, $40 \mathrm{nM}$ of purified recombinant proteins labeled with Cy5 were incubated for $10 \mathrm{~min}$ at $37^{\circ} \mathrm{C}$ with the indicated amount (titration experiment) or $75 \mathrm{nM}$ (single concentration experiment) of $40 \mathrm{~S}$ ribosomal subunits in ribosome assay buffer. For analysis of $80 \mathrm{~S}$ ribosome complex formation, $60 \mathrm{nM}$ of the indicated $40 \mathrm{~S}$ and $60 \mathrm{~S}$ ribosomal subunits, and $30 \mathrm{nM}$ of Cy5-labeled IRES were incubated for $10 \mathrm{~min}$ at $37^{\circ} \mathrm{C}$ in ribosome assay buffer with the indicated amount of $\mathrm{MgCl}_{2}$.

\section{Single-molecule spectroscopy}

For equilibrium experiments, $100 \mathrm{nM}$ refolded HCV IRES annealed to a biotinylated DNA oligo was incubated with $200 \mathrm{nM}$ of $40 S$ (RACK1-ybbR-Cy3) ribosomal subunits for $10 \mathrm{~min}$ at $37^{\circ} \mathrm{C}$ in ribosome assay buffer. Conditions were identical for experiments with 805 ribosomes except that $400 \mathrm{nM} 605$ ribosomal subunit was included and ribosome assay buffer was supplemented with $3 \mathrm{mM} \mathrm{Mg}(\mathrm{OAc})_{2}(5 \mathrm{mM}$ total). For experiments with in vitro reconstituted ribosomes, $1 \mu \mathrm{M}$ of $\triangle \mathrm{RACK} 140 \mathrm{~S}$ ribosomal subunits were first incubated with $2 \mu \mathrm{M}$ of Cy3-labeled recombinant protein for $10 \mathrm{~min}$ at $37^{\circ} \mathrm{C}$ in ribosome assay buffer, and subsequently, $200 \mathrm{nM}$ of in vitro reconstituted $40 \mathrm{~S}$ ribosomal subunits were incubated with refolded HCV IRES for $10 \mathrm{~min}$ at $37^{\circ} \mathrm{C}$ in ribosome assay buffer. Ribosome-IRES complexes were immobilized in a channel of neutravidin-coated quartz slides by addition of $40 \mu \mathrm{L} 400 \mathrm{pM}$ complex (based on the IRES concentration) and incubating for $5 \mathrm{~min}$. Unbound complexes were washed from the channel using ribosome assay buffer supplemented with $2 \mathrm{mM}$ Trolox (TSY), $2 \mathrm{mM}$ protocatechuic acid (PCA), and $0.06 \mathrm{U} / \mu \mathrm{L}$ protocatechuate-3,4-dioxygenase (PCD). Complexes were imaged using a prism-based total internal reflection fluorescence (TIRF) microscope as described previously (Aitken et al. 2008), using 532 and $647 \mathrm{~nm}$ excitation lasers with movies collected at five frames per second and EM gain set to 650. Short movies (50 frames) were collected using either (single) or both (dual) excitation lasers, whereas long movies (1500 frames) were collected using excitation with the $532 \mathrm{~nm}$ laser. Colocalized molecules were identified and analyzed using custom MATLAB (R2017a, MathWorks) scripts (available upon request). 
For real-time experiments in ZMWs, all imaging was conducted using a modified Pacific Biosystems RS II DNA sequencer as described previously (Chen et al. 2014; Johnson et al. 2018). ZMW chips purchased from Pacific Biosciences (PacBio) were initially washed with TP50 buffer $(50 \mathrm{mM}$ Tris-OAc pH 7.5, $100 \mathrm{mM}$ $\mathrm{KCl}$ ), coated with neutravidin by incubating $20 \mu \mathrm{L}$ of $75 \mathrm{nM}$ neutravidin in TP50 supplemented with blocking oligo for $5 \mathrm{~min}$, and washed 3-6x with ribosome assay buffer. 40S-IRES complexes were formed by incubating $1 \mu \mathrm{M} \triangle \mathrm{RACK} 140 \mathrm{~S}$ ribosomal subunits with $200 \mathrm{nM}$ refolded HCV IRES labeled at C44 with Cy3.5 annealed to a biotinylated DNA oligo. Complexes were immobilized on the neutravidin-coated ZMW surface by incubating $40 \mu \mathrm{L}$ of $1 \mathrm{nM}$ of complex (via the IRES) for $5 \mathrm{~min}$. Unbound complex was removed via 3-5 washes with ribosome assay buffer. Immediately before imaging, buffer was removed from the surface of the ZMW chip and replaced with $20 \mu \mathrm{L}$ ribosome assay buffer supplemented with $2 \mathrm{mM}$ TSY, $2 \mathrm{mM}$ PCA, and $0.06 \mathrm{U} /$ $\mu \mathrm{L} P C D$. Upon start of image acquisition, $20 \mu \mathrm{L}$ of Cy5-labeled recombinant protein in the same buffer was delivered to the chip surface. For experiments with delivery of $40 \mathrm{nM} 40 \mathrm{~S}-\mathrm{RACK} 1$ ybbR-Cy5, all conditions were the same except $40 \mu \mathrm{L}$ of $0.5 \mathrm{nM}$ HCV IRES labeled with either Cy3 or Cy3.5 at C44 was immobilized on the ZMW surface. All movies were collected at five frames per second for 20 min to maximize the capture of single-molecule photobleaching events of the Cy3.5 dye. Unless noted, the 532 $\mathrm{nm}$ laser was used at $0.8 \mu \mathrm{W} / \mu \mathrm{m}^{2}$ illumination and the temperature of the imaging chamber was $20^{\circ} \mathrm{C}$. The "low laser power" experiment was conducted using the $532 \mathrm{~nm}$ laser at $0.32 \mu \mathrm{W} / \mu \mathrm{m}^{2}$ illumination at $20^{\circ} \mathrm{C}$. All movies were analyzed using custom MATLAB scripts (available upon request) to extract fluorescence intensity and kinetic parameters. The respective ribosome, protein, and RNA samples were derived from a single purification for all equilibrium and real-time single-molecule analyses.

For the single-molecule analyses, $n$ represents the number of molecules that were analyzed, unless otherwise noted. For robust kinetic fits, we typically analyzed $>175$ molecules per condition, and only wells with a single IRES molecule, identified by a single-step photobleaching event of the donor fluorophore. To overcome nonuniform mixing on the surface of the ZMW chip, which occurs within $1 \mathrm{sec}$ at the center and is complete at $\sim 7 \mathrm{sec}$, we concentrated our analyses on molecules present in the center of the chip (Chen et al. 2014). At the lowest concentration (5 nM), the slow rate was dominant, and we were unable to confidently fit the association times with single or double exponential functions. For all analyses that compare smFRET efficiencies, smFRET events were assigned to a single state and single molecules were identified by a single-step photobleaching event of the donor fluorophore, based on relative fluorescence intensities. We then corrected the background fluorescence present in each optical channel and calculated distributions of observed smFRET efficiencies for the respective dye pairs.

The $30^{\circ} \mathrm{C}$ and $37^{\circ} \mathrm{C}$ real-time association experiments were conducted with the PacBio RS II imaging chamber set to $28^{\circ} \mathrm{C}$ and $35^{\circ} \mathrm{C}$, respectively, to account for the increased temperature due to laser excitation. We delivered RACK1 at $75 \mathrm{nM}$ for several reasons. First, the fast association rate was dominant, which enabled robust fitting of the data. Second, evaporation of the sample is a concern at the highest temperature in our microscope. We thus focused our measurements on the impact of temperature on fast binding events, which predominately occurred within $30 \mathrm{sec}$.
Third, this concentration was within a window that would allow observation of faster or slower binding events.

\section{DATA DEPOSITION}

The single-molecule data sets generated during and/or analyzed during the current study are available from the corresponding author upon request. All custom MatLab analysis scripts are available upon request or are available on GitHub (https://github .com/corsepius/FRETAutomation).

\section{SUPPLEMENTAL MATERIAL}

Supplemental material is available for this article.

\section{ACKNOWLEDGMENTS}

We are grateful to Alexey Petrov, Karim Majzoub, and Jan Carette's laboratory for helpful discussions. We thank Peter Sarnow and his laboratory for sharing cell culture equipment, and Miguel Mata for experimental advice on polysome profiling. We thank Oli Duss for helpful discussions and critical reading of the manuscript. Josh Yim and Matt Bogyo's laboratory generously shared equipment and knowledge for use of their HPLC for CoAdye purification. Ethan LaFontaine helped with cloning of RACK1ybbR into a lentiviral plasmid. The Stanford PAN facility provided support through mass mapping analysis, and thermal melt experiments were conducted at the ChEM-H MSKC. A.G.J. was supported by a National Science Foundation Graduate Research Fellowship (DGE-114747); C.P.L. is a Damon Runyon Fellow supported by the Damon Runyon Cancer Research Foundation (DRG\#2321-18); J.W. is supported by a postdoctoral scholarship from the Knut and Alice Wallenberg Foundation; N.C.C. is supported by a R35 grant from the National Institutes of Health in Michael Levitt's laboratory (GM122543); J.C. was supported by a Stanford Bio-X fellowship; and G.F. is supported by the University at Albany Faculty Research Awards Program (FRAP). Research on eukaryotic translation in the laboratory of J.D.P. is funded by the National Institutes of Health (AI047365, Al099506, and GM113078).

Received March 12, 2019; accepted April 21, 2019.

\section{REFERENCES}

Aitken CE, Marshall RA, Puglisi JD. 2008. An oxygen scavenging system for improvement of dye stability in single-molecule fluorescence experiments. Biophys J 94: 1826-1835. doi:10.1529/ biophysj.107.117689

Baum S, Bittins M, Frey S, Seedorf M. 2004. Asc1p, a WD40-domain containing adaptor protein, is required for the interaction of the RNA-binding protein Scp160p with polysomes. Biochem J 380: 823-830. doi:10.1042/bj20031962

Bjørndal B, Trave G, Hageberg I, Lillehaug JR, Raae AJ. 2003. Expression and purification of receptor for activated C-kinase 1 (RACK1). Protein Expr Purif 31: 47-55. doi:10.1016/S1046-5928 (03)00135-9

Blomen VA, Májek P, Jae LT, Bigenzahn JW, Nieuwenhuis J, Staring J, Sacco R, Van Diemen FR, Olk N, Stukalov A, et al. 2015. Gene 
essentiality and synthetic lethality in haploid human cells. Science 350: 1092-1096. doi:10.1126/science.aac7557

Blomqvist K, DiPetrillo C, Streva VA, Pine S, Dvorin JD. 2017. Receptor for activated C-kinase 1 (PfRACK1) is required for Plasmodium falciparum intra-erythrocytic proliferation. Mol Biochem Parasitol 211: 62-66. doi:10.1016/j.molbiopara.2016.10.002

Boehringer D, Thermann R, Ostareck-Lederer A, Lewis JD, Stark H. 2005. Structure of the hepatitis $C$ virus IRES bound to the human 80 S ribosome: remodeling of the HCV IRES. Structure 13: 16951706. doi:10.1016/j.str.2005.08.008

Buckhout-White S, Spillmann CM, Algar WR, Khachatrian A, Melinger JS, Goldman ER, Ancona MG, Medintz IL. 2014. Assembling programmable FRET-based photonic networks using designer DNA scaffolds. Nat Commun 5: 5615. doi:10.1038/ ncomms6615

Campeau E, Ruhl VE, Rodier F, Smith CL, Rahmberg BL, Fuss JO, Campisi J, Yaswen P, Cooper PK, Kaufman PD. 2009. A versatile viral system for expression and depletion of proteins in mammalian cells. PLoS One 4: e6529. doi:10.1371/journal.pone.0006529

Carette JE, Raaben M, Wong AC, Herbert AS, Obernosterer G, Mulherkar N, Kuehne Al, Kranzusch PJ, Griffin AM, Ruthel G, et al. 2011. Ebola virus entry requires the cholesterol transporter Niemann-Pick C1. Nature 477: 340-343. doi:10.1038/ nature 10348

Chen J, Dalal RV, Petrov AN, Tsai A, O'Leary SE, Chapin K, Cheng J, Ewan M, Hsiung P-L, Lundquist $P$, et al. 2014. High-throughput platform for real-time monitoring of biological processes by multicolor single-molecule fluorescence. Proc Natl Acad Sci 111: 664 669. doi:10.1073/pnas.1315735111

Cornish PV, Ermolenko DN, Noller HF, Ha T. 2008. Spontaneous intersubunit rotation in single ribosomes. Mol Cell 30: 578-588. doi:10 .1016/j.molcel.2008.05.004

Coyle SM, Gilbert WV, Doudna JA. 2009. Direct link between RACK1 function and localization at the ribosome in vivo. Mol Cell Biol 29: 1626-1634. doi:10.1128/MCB.01718-08

Defoiche J, Zhang Y, Lagneaux L, Pettengell R, Hegedus A, Willems L, Macallan DC. 2009. Measurement of ribosomal RNA turnover in vivo by use of deuterium-labeled glucose. Clin Chem 55: 1824 1833. doi:10.1373/clinchem.2008.119446

Dice JF, Schimke RT. 1972. Turnover and exchange of ribosomal proteins from rat liver. J Biol Chem 247: 98-111.

Fraser CS, Berry KE, Hershey JWB, Doudna JA. 2007. elF3j is located in the decoding center of the human $40 \mathrm{~S}$ ribosomal subunit. Mol Cell 26: 811-819. doi:10.1016/j.molcel.2007.05.019

Fuchs G, Petrov AN, Marceau CD, Popov LM, Chen J, O'Leary SE, Wang R, Carette JE, Sarnow P, Puglisi JD. 2015. Kinetic pathway of $40 S$ ribosomal subunit recruitment to hepatitis $C$ virus internal ribosome entry site. Proc Natl Acad Sci 112: 319-325. doi:10 .1073/pnas.1421328111

Gallo S, Ricciardi S, Manfrini N, Pesce E, Oliveto S, Mancino M, Maffioli E, Moro M, Crosti M, Bombaci M, et al. 2018. RACK1 specifically regulates translation through its binding to ribosomes. Mol Cell Biol 38: e00230-18. doi:10.1128/MCB.00230-18

Gerbasi VR, Weaver CM, Hill S, Friedman DB, Link AJ. 2004. Yeast Asc1p and mammalian RACK1 are functionally orthologous core $40 \mathrm{~S}$ ribosomal proteins that repress gene expression. Mol Cell Biol 24: 8276-8287. doi:10.1128/MCB.24.18.8276-8287.2004

Gibson TJ. 2012. RACK1 research-ships passing in the night? FEBS Lett 586: 2787-2789. doi:10.1016/j.febslet.2012.04.048

Gilbert WV. 2011. Functional specialization of ribosomes? Trends Biochem Sci 36: 127-132. doi:10.1016/j.tibs.2010.12.002

Gleitsman KR, Sengupta RN, Herschlag D. 2017. Slow molecular recognition by RNA. RNA 23: 1745-1753. doi:10.1261/rna.062026 .117
Hafirassou ML, Meertens L, Delaugerre C, Labeau A, Vidalain P-O, Dejarnac O, Umaña-Diaz C, Bonnet-Madin L, Kümmerer BM, Roingeard $P$, et al. 2017. A global interactome map of the dengue virus NS1 identifies virus restriction and dependency host factors. Cell Rep 21: 3900-3913. doi:10.1016/j.celrep.2017.11.094

Jha S, Rollins MG, Fuchs G, Procter DJ, Hall EA, Cozzolino K, Sarnow P, Savas JN, Walsh D. 2017. Trans-kingdom mimicry underlies ribosome customization by a poxvirus kinase. Nature 546: 651-655. doi:10.1038/nature22814

Johnson AG, Grosely R, Petrov AN, Puglisi JD. 2017. Dynamics of IRES-mediated translation. Philos Trans $R$ Soc B Biol Sci 372: 20160177. doi:10.1098/rstb.2016.0177

Johnson AG, Petrov AN, Fuchs G, Majzoub K, Grosely R, Choi J, Puglisi JD. 2018. Fluorescently-tagged human elF3 for single-molecule spectroscopy. Nucleic Acids Res 46: e8. doi:10.1093/nar/ gkx1050

Juszkiewicz S, Hegde RS. 2017. Initiation of quality control during poly (A) translation requires site-specific ribosome ubiquitination. Mol Cell 65: 743-750. doi:10.1016/j.molcel.2016.11.039

Juszkiewicz S, Chandrasekaran V, Lin Z, Kraatz S, Ramakrishnan V, Hegde RS. 2018. ZNF598 is a quality control sensor of collided ribosomes. Mol Cell 72: 469-481. doi:10.1016/j.molcel.2018.08 .037

Kaiser CM, Goldman DH, Chodera JD. 2011. Nascent protein folding. Science 334: 1723-1727. doi:10.1126/science.1209740

Kim HS, Lee K, Kim SJ, Cho S, Shin HJ, Kim C, Kim JS. 2018. Arrayed CRISPR screen with image-based assay reliably uncovers host genes required for coxsackievirus infection. Genome Res 28: 859-868. doi:10.1101/gr.230250.117

Kossinova OA, Malygin AA, Babailova ES, Karpova GG. 2008. Binding of human ribosomal protein $\mathrm{p} 40$ and its truncated mutants to the small ribosomal subunit. Mol Biol 42: 911-916. doi:10.1134/ S0026893308060125

Kuroha K, Akamatsu M, Dimitrova L, Ito T, Kato Y, Shirahige K, Inada T. 2010. Receptor for activated $C$ kinase 1 stimulates nascent polypeptide-dependent translation arrest. EMBO Rep 11: 956-961. doi:10.1038/embor.2010.169

Lancaster AM, Jan E, Sarnow P. 2006. Initiation factor-independent translation mediated by the hepatitis $C$ virus internal ribosome entry site. RNA 12: 894-902. doi:10.1261/rna.2342306

Larburu N, Montellese C, O'Donohue MF, Kutay U, Gleizes PE, Plisson-Chastang C. 2016. Structure of a human pre-40S particle points to a role for RACK1 in the final steps of $18 \mathrm{~S}$ rRNA processing. Nucleic Acids Res 44: 8465-8478. doi:10.1093/nar/gkw714

Lieberman KR, Firpo MA, Herr AJ, Nguyenle T, Atkins JF, Gesteland RF, Noller HF. 2000. The 23 S rRNA environment of ribosomal protein L9 in the $50 \mathrm{~S}$ ribosomal subunit. J Mol Biol 297: 1129-1143. doi:10.1006/jmbi.2000.3621

Majzoub K, Hafirassou ML, Meignin C, Goto A, Marzi S, Fedorova A, Verdier Y, Vinh J, Hoffmann JA, Martin F, et al. 2014. RACK1 controls IRES-mediated translation of viruses. Cell 159: 1086-1095. doi:10.1016/j.cell.2014.10.041

Mathis AD, Naylor BC, Carson RH, Evans E, Harwell J, Knecht J, Hexem E, Peelor FF, Miller BF, Hamilton KL, et al. 2017. Mechanisms of in vivo ribosome maintenance change in response to nutrient signals. Mol Cell Proteomics 16:243-254. doi:10.1074/ mcp.M116.063255

Matsuo Y, Ikeuchi K, Saeki Y, Iwasaki S, Schmidt C, Udagawa T, Sato F, Tsuchiya H, Becker $T$, Tanaka $K$, et al. 2017. Ubiquitination of stalled ribosome triggers ribosome-associated quality control. Nat Commun 8: 159. doi:10.1038/s41467-017-00188-1

May KL, Li X-P, Martínez-Azorín F, Ballesta JPG, Grela P, Tchórzewski M, Tumer NE. 2012. The P1/P2 proteins of the human ribosomal stalk are required for ribosome binding and 
depurination by ricin in human cells. FEBS J 279: 3925-3936. doi:10.1111/j.1742-4658.2012.08752.x

Melnikov S, Ben-Shem A, Garreau De Loubresse N, Jenner L, Yusupova G, Yusupov M. 2012. One core, two shells: bacterial and eukaryotic ribosomes. Nat Struct Mol Biol 19: 560-567. doi:10.1038/nsmb.2313

Mizuno CM, Guyomar C, Roux S, Lavigne R, Rodriguez-Valera F, Sullivan M, Gillet R, Forterre P, Krupovic M. 2019. Numerous cultivated and uncultivated viruses encode ribosomal proteins. Nat Commun 10: 752. doi:10.1038/s41467-019-08672-6

Nery FC, Bressan GC, Alborghetti MR, Passos DO, Kuniyoshi TM, Ramos CH, Oyama S Jr, Kobarg J. 2006. A spectroscopic analysis of the interaction between the human regulatory proteins RACK1 and Ki-1/57. Biol Chem 387: 577-582. doi:10.1515/BC.2006.074

Nielsen MH, Flygaard RK, Jenner LB. 2017. Structural analysis of ribosomal RACK1 and its role in translational control. Cell Signal 35: 272-281. doi:10.1016/j.cellsig.2017.01.026

Nierhaus KH, Dohme F. 1974. Total reconstitution of functionally active $50 S$ ribosomal subunits from Escherichia coli. Proc Natl Acad Sci 71: 4713-4717. doi:10.1073/pnas.71.12.4713

Nikolov EN, Dineva BB, Dabeva MD, Nikolov TK. 1987. Turnover of ribosomal proteins in regenerating rat liver after partial hepatectomy. Int J Biochem 19: 159-163. doi:10.1016/0020-711X(87) 90326-0

Quade N, Boehringer D, Leibundgut M, Van Den Heuvel J, Ban N. 2015. Cryo-EM structure of Hepatitis $C$ virus IRES bound to the human ribosome at 3.9-Å resolution. Nat Commun 6: 7646. doi:10 $.1038 /$ ncomms 8646

Rabl J, Rabl J, Leibundgut M, Ataide SF, Haag A, Ban N. 2011. Ribosomal subunit in complex with initiation factor 1 . Science 331: 730-737. doi:10.1126/science.1198308

Ruiz Carrillo D, Chandrasekaran R, Nilsson M, Cornvik T, Liew CW, Tan SM, Lescar J. 2012. Structure of human Rack1 protein at a resolution of $2.45 \AA$ A. Acta Crystallogr Sect F Struct Biol Cryst Commun 68: 867-872. doi:10.1107/S1744309112027480

Schreiber G. 2002. Kinetic studies of protein-protein interactions. Curr Opin Struct Biol 12: 41-47. doi:10.1016/S0959-440X(02) 00287-7

Sengupta J, Nilsson J, Gursky R, Spahn CMT, Nissen P, Frank J. 2004. Identification of the versatile scaffold protein RACK1 on the eukaryotic ribosome by cryo-EM. Nat Struct Mol Biol 11: 957-962. doi:10.1038/nsmb822

Shi Z, Fujii K, Kovary KM, Genuth NR, Röst HL, Teruel MN, Barna M. 2017. Heterogeneous ribosomes preferentially translate distinct subpools of mRNAs genome-wide. Mol Cell 67: 71-83. doi:10 .1016/j.molcel.2017.05.021

Shigeoka T, Koppers M, Wong HHW, Lin JQ, Dwivedy A, de Freitas Nascimento J, Cagnetta R, van Tartwijk F, Strohl F, Cioni J-M, et al. 2018. On-site ribosome remodeling by locally synthesized ribosomal proteins in axons. bioRxiv doi:10.1101/500033

Sitron CS, Park JH, Brandman O. 2017. Asc1, Hel2, and Slh1 couple translation arrest to nascent chain degradation. RNA 23: 798810. doi:10.1261/rna.060897.117

Sokabe M, Fraser CS. 2018. Toward a kinetic understanding of eukaryotic translation. Cold Spring Harb Perspect Biol 11: a032706. doi:10.1101/cshperspect.a032706

Steffen KK, McCormick MA, Pham KM, Mackay VL, Delaney JR, Murakami CJ, Kaeberlein M, Kennedy BK. 2012. Ribosome deficiency protects against ER stress in Saccharomyces cerevisiae. Genetics 191: 107-118. doi:10.1534/genetics.111.136549
Stirnimann CU, Petsalaki E, Russell RB, Müller CW. 2010. WD40 proteins propel cellular networks. Trends Biochem Sci 35: 565-574. doi:10.1016/j.tibs.2010.04.003

Sun M, Li W, Blomqvist K, Das S, Hashem Y, Dvorin JD, Frank J. 2015. Dynamical features of the Plasmodium falciparum ribosome during translation. Nucleic Acids Res 43: 10515-10524. doi:10 .1093/nar/gkv991

Sundaramoorthy E, Leonard M, Mak R, Liao J, Fulzele A, Bennett EJ. 2017. ZNF598 and RACK1 regulate mammalian ribosome-associated quality control function by mediating regulatory $40 \mathrm{~S}$ ribosomal ubiquitylation. Mol Cell 65: 751-760. doi:10.1016/j.molcel .2016 .12 .026

Thompson MK, Rojas-Duran MF, Gangaramani P, Gilbert WV. 2016. The ribosomal protein Asc1/RACK1 is required for efficient translation of short mRNAs. elife 5: e11154. doi:10.7554/eLife.11154

Traub P, Nomura M. 1968. Structure and function of $E$. coli ribosomes. V. Reconstitution of functionally active $30 \mathrm{~S}$ ribosomal particles from RNA and proteins. Proc Natl Acad Sci 59: 777784. doi:10.1073/pnas.59.3.777

Uemura S, Aitken CE, Korlach J, Flusberg BA, Turner SW, Puglisi JD. 2010. Real-time tRNA transit on single translating ribosomes at codon resolution. Nature 464: 1012-1017. doi:10.1038/ nature08925

Van De Waterbeemd M, Tamara S, Fort KL, Damoc E, Franc V, Bieri P, Itten M, Makarov A, Ban N, Heck AJR. 2018. Dissecting ribosomal particles throughout the kingdoms of life using advanced hybrid mass spectrometry methods. Nat Commun 9: e2493. doi:10 .1038/s41467-018-04853-x

Volta V, Beugnet A, Gallo S, Magri L, Brina D, Pesce E, Calamita P, Sanvito F, Biffo S. 2013. RACK1 depletion in a mouse model causes lethality, pigmentation deficits and reduction in protein synthesis efficiency. Cell Mol Life Sci 70: 1439-1450. doi:10.1007/ s00018-012-1215-y

Wang L, Pulk A, Wasserman MR, Feldman MB, Altman RB, Doudna Cate JH, Blanchard SC. 2012. Allosteric control of the ribosome by small-molecule antibiotics. Nat Struct Mol Biol 19: 957-963. doi:10.1038/nsmb.2360

Warner JR, Mclntosh KB. 2009. How common are extraribosomal functions of ribosomal proteins? Mol Cell 34: 3-11. doi:10.1016/ j.molcel.2009.03.006

Wong W, Bai XC, Brown A, Fernandez IS, Hanssen E, Condron M, Tan YH, Baum J, Scheres SHW. 2014. Cryo-EM structure of the Plasmodium falciparum $80 \mathrm{~S}$ ribosome bound to the anti-protozoan drug emetine. eLife 3: e03080. doi:10.7554/eLife.03080

Xue S, Barna M. 2012. Specialized ribosomes: a new frontier in gene regulation and organismal biology. Nat Rev Mol Cell Biol 13: 355369. doi:10.1038/nrm3359

Yamamoto H, Unbehaun A, Loerke J, Behrmann E, Collier M, Bürger J, Mielke T, Spahn CMT. 2014. Structure of the mammalian $80 \mathrm{~S}$ initiation complex with initiation factor 5B on HCV-IRES RNA. Nat Struct Mol Biol 21: 721-727. doi:10.1038/nsmb.2859

Yamamoto H, Collier M, Loerke J, Ismer J, Schmidt A, Hilal T, Sprink T, Yamamoto K, Mielke T, Bürger J, et al. 2015. Molecular architecture of the ribosome-bound Hepatitis $C$ Virus internal ribosomal entry site RNA. EMBO J 34: 3042-3058. doi:10.15252/embj .201592469

Yin J, Lin AJ, Golan DE, Walsh CT. 2006. Site-specific protein labeling by Sfp phosphopantetheinyl transferase. Nat Protoc 1: 280-285. doi:10.1038/nprot.2006.43 

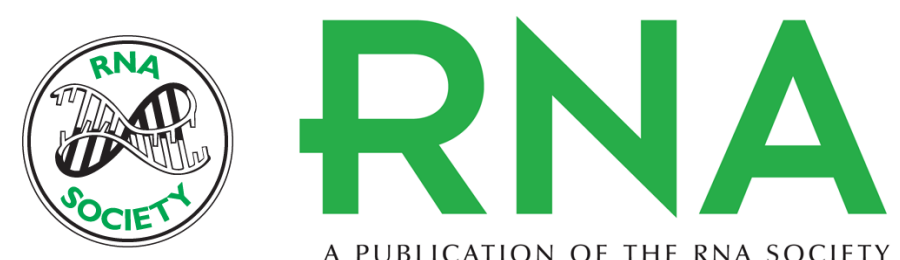

A PUBLICATION OF THE RNA SOCIETY

\section{RACK1 on and off the ribosome}

Alex G. Johnson, Christopher P. Lapointe, Jinfan Wang, et al.

RNA 2019 25: 881-895 originally published online April 25, 2019

Access the most recent version at doi:10.1261/rna.071217.119

Supplemental Material

References

Creative Commons License

Email Alerting Service
http://rnajournal.cshlp.org/content/suppl/2019/04/25/rna.071217.119.DC1

This article cites 69 articles, 22 of which can be accessed free at: http://rnajournal.cshlp.org/content/25/7/881.full.html\#ref-list-1

This article is distributed exclusively by the RNA Society for the first 12 months after the full-issue publication date (see http://rnajournal.cshlp.org/site/misc/terms.xhtml). After 12 months, it is available under a Creative Commons License (Attribution-NonCommercial 4.0 International), as described at http://creativecommons.org/licenses/by-nc/4.0/.

Receive free email alerts when new articles cite this article - sign up in the box at the top right corner of the article or click here. 